\section{ITC 4/46}

Journal of Information Technology and Control

Vol. 46/No. 4/ 2017

pp. 546-565

DOI 10.5755/j01.itc.46.4.15391

(C) Kaunas University of Technology

\section{Monte-Carlo Based Optimal Control Strategy Through State Estimator in Autonomous Space Systems}

Received 2016/06/26

Accepted after revision 2017/10/05

\title{
Monte-Carlo Based Optimal Control Strategy Through State Estimator in Autonomous Space Systems
}

\author{
A. H. Mazinan \\ Department of Control Engineering, Faculty of Electrical Engineering, South Tehran Branch, Islamic Azad \\ University, (IAU), No. 209, North Iranshahr St., P.O. Box 11365/4435, Tehran, Iran, tel: +98 2188830826 30/ \\ +982133 72 28 31-5x3211 (Office): fax: +982188 830831
}

Corresponding author: mazinan@azad.ac.ir

What we research here deals with the dynamics and its kinematics concerning the autonomous space systems through a new control strategy, while a band of parameters uncertainties in connection with disturbances based upon the variations of the thrust vector, center of mass, engine misalignment, moments of inertial and so on are all taken into real consideration. To present the investigated outcomes in such a real situation, the process noise that is related to a set of thrusters and the measurement noise that also is related to a set of sensors are considered to be dealt with through optimal state estimator scheme. There are the double control loops including the inner loop and the outer loop, which are organized based upon a combination of low and high thrusts levels to handle three-axis rotational angles and their rates. The aforementioned thrusts levels in connection with the uncertainties and disturbances are handled through the Monte-Carlo based method to consider the performance of the proposed approach, in a series of experiments. The investigated results show that the performance of the proposed strategy is verified in which the well-known state-dependent Riccati equation based on the three-axis rotational angles and the corresponding angular rates as well as a number of potential benchmarks are considered to be compared in the same conditions as much as possible.

KEYWORDS: Monte-Carlo based method, optimal control strategy, state estimator, autonomous space systems, a band of uncertainties, disturbances. 


\section{Introduction}

With the development of space system technologies, the traditional solutions do not have the sufficient merit to deal with such a system under control. In making an effort to outperform the control strategy performance, the proposed idea is presented based upon an integration of low and high thrusts levels in connection with a band of parameters uncertainties and disturbances to handle the dynamics and its kinematics of the space system. In a word, to consider the investigated outcomes in a real situation, the variations of the thrust vector, center of mass, engine misalignment, moment of inertial and so on, are taken into real consideration to provide three-axis disturbances. With this goal, the process noise in correspondence with a set of thrusters and also the measurement noise in correspondence with a set of sensors are considered to be dealt with through optimal state estimator scheme. It is to note that the proposed control strategy is to organize the double control loops including the inner loop and the outer loop that are designed in line with the aforementioned combination of low and high thrusts levels to deal with three-axis rotational angles and their rates, accurately. There are a number of on-off reaction thrusters and a set of the pulsewidth pulse-frequencies ( $P W P F s$ ) in association with the control allocations $(C A s)$ to guarantee the system performance. In fact, the performance of the proposed control strategy is considered through thrusts levels in connection with the uncertainties and disturbances to be evaluated in the Monte-Carlo based method in a series of experiments with different scenarios. In addition, the present consideration is finalized by designing the state-dependent Riccati equation (SDRE) based on the rotational angles in line with their rates, as the well-known optimal control approach, to verify the system performance to be compared in the same conditions. Now, in order to evaluate the contribution of the control strategy proposed, a collection of the potential methods, which most of them are recently investigated in this area are briefly focused.

With this goal, Allende-Alba and Montenbruck's proposed the robust and precise baseline determination of distributed system [1]. Cpalka et al. considered a new approach, in order to design the control system through the genetic programming [2]. Distributed finite-time attitude regulation via bounded control is considered by Cheng et al. [3]. Dong et al.'s work investigat- ed the dual-quaternion based fault-tolerant control for the formation flying with finite-time convergence [4]. Doroshin's research work dealt with hetero clinic chaos and its local suppression in attitude dynamics of an asymmetrical dual-spin system [5]. Felicetti and Palmerini considered analytical and numerical investigations on formation control through electrostatic forces and also by means of electrostatic forces [6-7]. In the Garmendia et al.'s work, a calculation of conductive conductances in complex geometries, in its accurate model, is considered [8-9]. Guo et al. analyzed finite-time output feedback attitude coordination control for formation flying without unwinding [10].

He and Jie's research coped with the leader-following attitude control concerning multiple rigid spacecraft [11]. Huang et al. focused on robust tracking cubature Kalman filter for attitude estimation with quaternion constraint [12]. Jia and Yang offered an optimization of control parameters based on the genetic algorithms for attitude tracking with input constraints [13]. Kim et al.'s research presented attitude control using neuro-fuzzy approximation regarding the optimal controllers [14]. Zhao and Jia's research organized neural network-based distributed adaptive attitude synchronization control of formation under modified fast terminal sliding mode [15]. Mirshams and Khosrojerdi investigated the attitude control for the underactuated system through tube-based model predictive control approach [16]. Mazinan and Shakhesi proposed the autonomous systems control incorporating automated maneuvers strategies in the presence of parameters uncertainties [17]. Stability analysis of autonomous systems in the presence of large disturbances based upon the Lyapunov-based constrained control strategy and also the comprehensive cascade control strategy considering a class of overactuated autonomous non-rigid systems with model uncertainties are considered as well [18-19]. High-performance robust three-axis finite-time attitude control approach using quaternion based estimation scheme is investigated [20]. Ni et al.'s research work addressed time-varying modal parameters identification with rotating flexible appendage by recursive algorithm [21]. Peng and Jaing suggested nonlinear receding horizon guidance for formation reconfiguration on liberation point orbits using a simplistic numerical method [22]. Stevenson and Schaub's research dealt with electrostatic rate and attitude control through experimental results and performance considerations [23]. 
Schwartz et al.'s and Cheng et al.'s works are related to small-body deflection techniques [24]. Sidi presented academically fundamental practical approaches in dynamical modeling and its control [25]. Shahi and Mazinan presented cascade control approach [26]. Schulte and Spencer's research developed the integrated guidance, navigation and control systems for automated proximity operations [27]. Wang et al.'s work designed the decentralized relative navigation algorithm for the formation flying [28]. Zou et al.'s research work distributed attitude synchronization control for a group of flexible systems through attitude measurements and finite-time velocity-free attitude coordination formations control [29-30]. Zhang et al. quoted attitude stabilization of rigid system with disturbance, generated by time varying uncertain exosystems [31]. Finally, Zhang and Duan's research dealt with the integrated translational and rotational finite-time maneuver regarding the rigid spacecraft under actuator misalignment [32].

The key core of finding the new results in the strategy proposed is twofold. The first one is based on the realization of a unique three-axis comprehensive control structure that is able to deal with a class of the space systems under control with a set of parameters uncertainties and disturbances. The second one is related to the investigated outcomes that are accurate with respect to the predefine mission operation plans through a Monte-Carlo based method.

The rest of the manuscript is organized as follows: the proposed control strategy, including a brief discussion of the space system dynamics, the overall strategy realization, the optimal estimation scheme, the $P W P F-C A$ realization, the uncertainties and the disturbances and finally the SDRE control benchmark, are first presented in Section 2. The simulation results, including the first to fourth experiment and the verification of the strategy are presented in Section 3. The conclusion is finally presented in Section 4.

\section{The Proposed Control Strategy}

\subsection{A Brief Discussion of the Mathematical Model Regarding the Space System Dynamics}

The attitude dynamics as a mathematical model of the space system in the matrix form is first represented based on the following equation [25]

$$
M(t)_{3 \times 1}=\frac{d H(t)_{3 \times 1}}{d t}+\omega_{s}(t)_{3 \times 1} \times H(t)_{3 \times 1},
$$

where $M(t)$ denotes the three-axis control torques containing $M_{\mu}(t), \mu=x, y, z, H(t)$ denotes the angular momentum vector in the body coordinate containing $H_{\mu}(t)=I_{\mu}(t) \omega_{s \mu}(t), \mu=x, y, z, \omega_{s}(t)$ denotes the angular rate vector in the body coordinate, which contains $\omega_{s \mu}(t)$ and the notation of " $\times$ " means the cross product, as well. Now, by addressing the above-captioned three-axis angular rates, the above-captioned three-axis control torques of the aforementioned space system are correspondingly realized as

$$
\left\{\begin{array}{l}
M_{x}(t)=\dot{H}_{x}(t)+\omega_{s y}(t) H_{z}(t)-\omega_{s z}(t) H_{y}(t) \\
M_{y}(t)=\dot{H}_{y}(t)+\omega_{s z}(t) H_{x}(t)-\omega_{s x}(t) H_{z}(t) \\
M_{z}(t)=\dot{H}_{z}(t)+\omega_{s x}(t) H_{y}(t)-\omega_{s y}(t) H_{x}(t)
\end{array}\right.
$$

Moreover, the above-referenced attitude dynamics equations are easily resulted by

$$
\left\{\begin{array}{l}
\dot{\omega}_{s x}(t)=\frac{M_{x}(t)}{I_{x}(t)}-\frac{\left(I_{z}(t)-I_{y}(t)\right)}{I_{x}(t)} \omega_{s y}(t) \omega_{s z}(t) \\
\dot{\omega}_{s y}(t)=\frac{M_{y}(t)}{I_{y}(t)}-\frac{\left(I_{x}(t)-I_{z}(t)\right)}{I_{y}(t)} \omega_{s x}(t) \omega_{s z}(t) \\
\dot{\omega}_{s z}(t)=\frac{M_{z}(t)}{I_{z}(t)}-\frac{\left(I_{y}(t)-I_{x}(t)\right)}{I_{z}(t)} \omega_{s x}(t) \omega_{s y}(t) .
\end{array}\right.
$$

In the strategy proposed, the state space model of the aforementioned space system can correspondingly be represented through

$\dot{x}(t)_{6 \times 1}=A(t)_{6 \times 6} x(t)_{6 \times 1}+B(t)_{6 \times 3} u(t)_{3 \times 1}$,

where $x(t)$ by addressing rotational angles, i.e. $\varphi_{s}(t), \theta_{s}(t)$ and $\psi_{\mathrm{s}}(t)$ as well as $u(t)$ are taken as

$$
\boldsymbol{x}(\boldsymbol{t})=\left[\begin{array}{c}
\boldsymbol{\omega}_{\boldsymbol{s} \boldsymbol{x}, \boldsymbol{y}, \mathbf{z}}(\boldsymbol{t}) \\
\varphi_{s}(t) \\
\theta_{s}(t) \\
\psi_{s}(t)
\end{array}\right],
$$

$u(t)=M_{x, y, z}(t)$.

$A(t)$ and $B(t)$ by focusing on " $O$ " as the initial values of the system under control are formulated as follows 


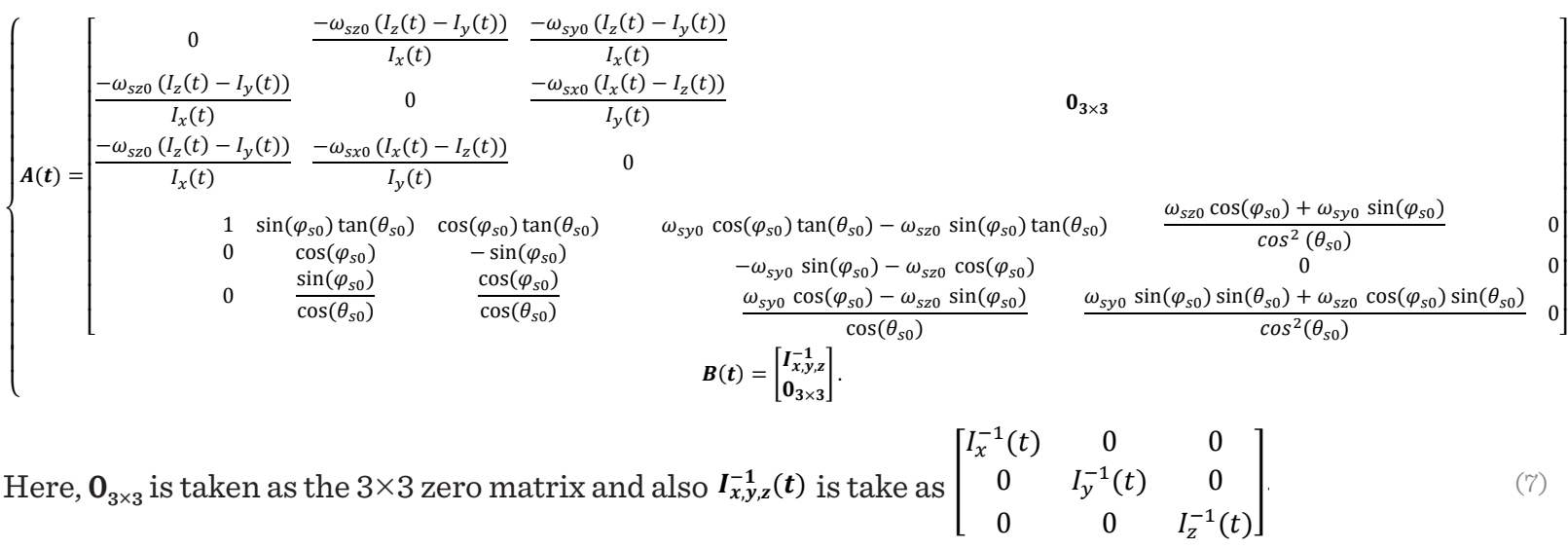

\subsection{The Uncertainties and the Disturbances Regarding the Mathematical Model}

The uncertainties of the system under control are subject to the variations of $\Delta I_{\mu}(t)$ with respect to time to provide $I_{\mu}(t)=I_{\mu 0}+\Delta I_{\mu}(t)$ in correspondence with the disturbances that are taken into consideration in the mathematical model of the aforementioned space system by focusing on the variations of the thrust vector $\left(\boldsymbol{F}_{I}(\boldsymbol{t})\right)$ engine misalignments $\left(\varphi_{D I}(t), \theta_{D I}(t), \psi_{D I}(t)\right)$, and engine $\operatorname{arm}\left(\boldsymbol{r}_{I}(\boldsymbol{t})\right)$ to be changed upon the variation of the center of mass $\left(\Delta c_{g_{I}}(t)\right)$, as input sources. The idea of providing the present disturbances is entirely inspired of the following equation [25]

$$
\begin{aligned}
& \boldsymbol{M}_{\boldsymbol{D}}(\boldsymbol{t})_{3 \times \mathbf{1}}= \\
& \boldsymbol{D}\left(\varphi_{D I}(t), \theta_{D I}(t), \psi_{D I}(t)\right)_{\mathbf{3} \times \mathbf{3}}\left(\boldsymbol{L}(\boldsymbol{t})_{3 \times \mathbf{1}} \times \boldsymbol{F}_{\boldsymbol{I}}(\boldsymbol{t})_{3 \times \mathbf{1}}\right)
\end{aligned}
$$

The outcomes are finalized, as long as the matrix multiplication (MMP) of the direction cosine matrix $(D)$ of the misalignments profile can be multiplied in cross form by $L(t)=\boldsymbol{r}_{I}(t)+\Delta \boldsymbol{c}_{g I}(t)$ deviation profile, at each instant of time. The profile of these parameters is updated as $\varphi_{D}(t), \theta_{D}(t), \psi_{D}(t), \boldsymbol{F}(\boldsymbol{t})$ and $\Delta \boldsymbol{c}_{g}(\boldsymbol{t})$ through uncertainties by multiplying to $K_{D}(t), K_{C}(t)$ and $K_{F}(t)$, respectively, that are randomly taken along with Monte-Carlo based method

$$
\left\{\begin{aligned}
\varphi_{D}(t) & =K_{D}(t) \varphi_{D I}(t) \\
\theta_{D}(t) & =K_{D}(t) \theta_{D I}(t) \\
\psi_{D}(t) & =K_{D}(t) \psi_{D I}(t) \\
\Delta \boldsymbol{c}_{\boldsymbol{g}}(t) & =K_{C}(t) \Delta \boldsymbol{c}_{\boldsymbol{g} \boldsymbol{I}}(t) \\
\boldsymbol{F}(t) & =K_{F}(t) \boldsymbol{F}_{\boldsymbol{I}}(t) .
\end{aligned}\right.
$$

It is to note that the $\boldsymbol{M}(\boldsymbol{t})$ in Eq. (1) should be considered in line with the final outcomes of $\boldsymbol{M}_{D}(t)$ as disturbances to provide $\boldsymbol{M}(\boldsymbol{t})+\boldsymbol{M}_{D}(t)$ for the purpose of applying to the space system under control, at each instant of time.

\subsection{The Overall Strategy Realization}

The realization of the overall strategy is presented to deal with the dynamics and its kinematics of the space system under control along with the integrations of so many employed modules, as is illustrated in Fig. 2. There are the double closed loops including the inner loop and the corresponding outer loop to deal with the three-axis rotational angles and their rates.

It is to note that the outer loop is handled through Contl $_{L H}$ in correspondence with the proportional-integral-derivative approach, which is related to low-high thrusts control. The inner loop is handled through $R F_{L H}$ in correspondence with the proportional approach, which is related to the same low-high thrust control. The $P W P F-C A_{L H}$ is employed to provide a sequence of on-off thrusts in response to the on-off reaction thrusters and also to provide a large number of thrusts controls in response to the number of the same reaction thrusters, as well. The strategy proposed is organized in the presence of noise, disturbances and parameters uncertainties. The noises, including the measurement noise that is related to the sensors of the system under control and also process noise that is also related to the reaction thrusters, are taken into consideration, while the optimal estimator is designed to filter the aforementioned ones to avoid passing to the strategy. A number of the parameters of the system, 
Figure 1

The schematic diagram of the control strategy

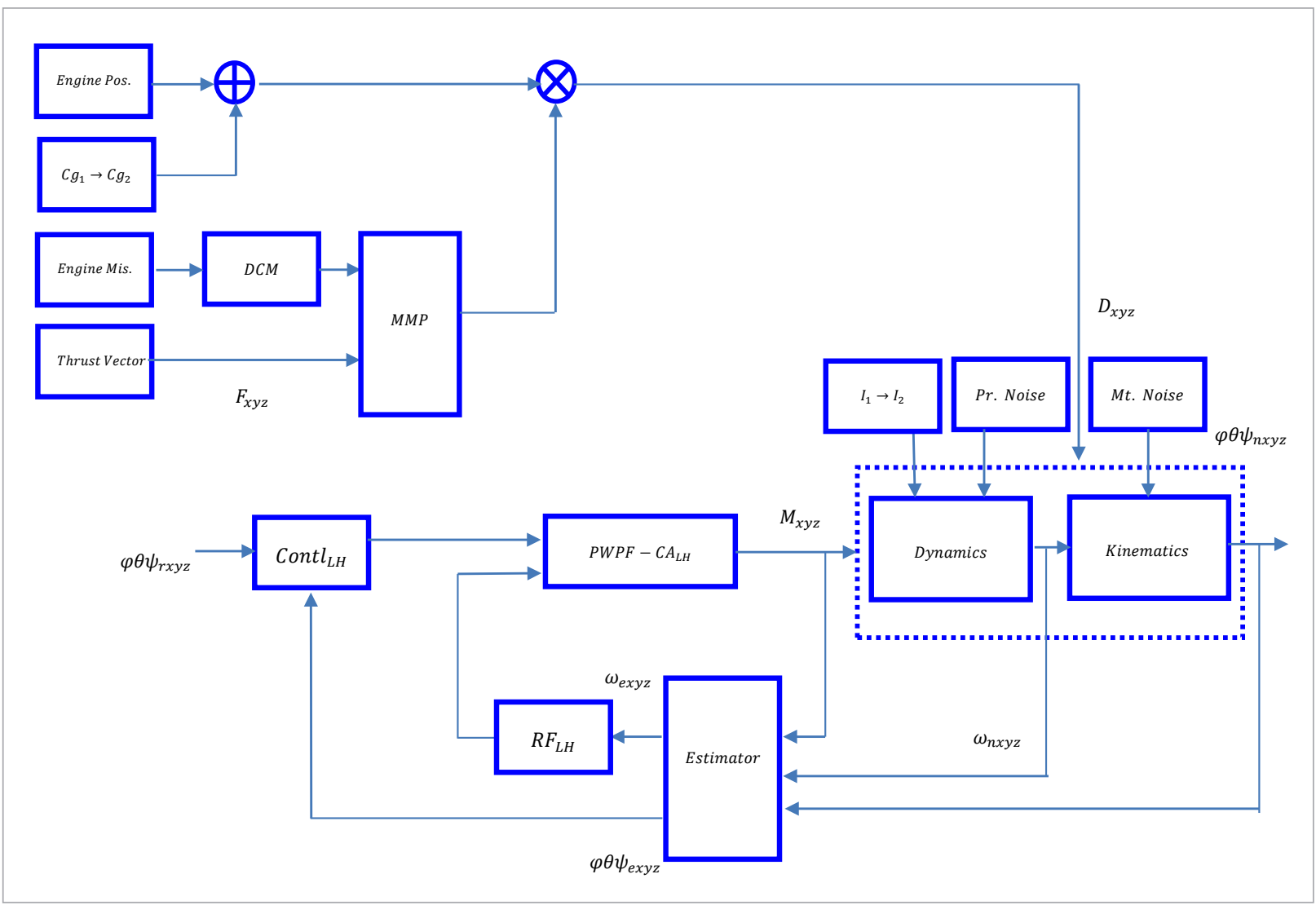

including the center of gravity through $c_{g_{1}} \rightarrow c_{g_{2}}$ and the moments of inertial through $I_{1} \rightarrow I_{2}$ are varied with respect to time. Moreover, the thrust vector and the engine misalignments are instantly varied to provide the aforementioned parameters uncertainties and the disturbances. The detailed information of a number of modules is considered in the proceeding sub-sections.

\subsection{The Optimal Estimation Scheme}

The optimal estimation, designed in the proposed control strategy, is based upon the well-known Kalman filter scheme. In brief, it can be considered by addressing the general known form of the continuous system, given in Eq. (4), including the state and its measurement equations as [12]

$$
\left\{\begin{array}{c}
\dot{x}(t)=A x(t)+B u(t)+G w(t) \\
y(t)=C x(t)+D u(t)+H w(t)+v(t)
\end{array}\right.
$$

where $\boldsymbol{x}(\boldsymbol{t})$ and $\boldsymbol{u}(\boldsymbol{t})$ are taken as Eqs. (5)-(6) and $\boldsymbol{y}(\boldsymbol{t})$ is also related to the output of the system, respectively. Here, $\boldsymbol{A}, \boldsymbol{B}, \boldsymbol{C}, \boldsymbol{D}, \boldsymbol{G}$, and $\boldsymbol{H}$ are related to the system parameters with noise, while $\boldsymbol{w}(t)$ and $\boldsymbol{v}(\boldsymbol{t})$ are related to the white process noise and the white measurement noise, respectively, satisfying Eq. (11)

$$
\left\{\begin{array}{c}
E(w(t))=E(v(t))=0 \\
E\left(w(t) w^{T}(t)\right)=Q \\
E\left(v(t) v^{T}(t)\right)=R \\
E\left(w(t) v^{T}(t)\right)=N
\end{array}\right.
$$

where $E($.) denotes the expected value by the following equation

$$
P=\lim _{t \rightarrow \infty} E\left(\left(x(t)-\widehat{x}(t)\left(x(t)-\widehat{x}(t)^{T}\right) .\right.\right.
$$

Here, the estimated state, i.e. $\widehat{\boldsymbol{x}}(\boldsymbol{t})$ is expressed as 


$$
\widehat{\boldsymbol{x}}(\boldsymbol{t})=\left[\begin{array}{c}
\boldsymbol{\omega}_{\boldsymbol{e x} \boldsymbol{y}, \boldsymbol{z}}(\boldsymbol{t}) \\
\varphi_{e}(t) \\
\theta_{e}(t) \\
\psi_{e}(t)
\end{array}\right] .
$$

The outcomes are also used to minimize the steadystate error covariance through

$$
\dot{\hat{x}}(t)=A \widehat{x}(t)+B u(t)+L(y(t)-C \widehat{x}(t)-D u(t)) .(14)
$$

The optimal estimated solutions for $y(t)$ and $x(t)$ can be unified by using Eq. (15)

$$
\left[\begin{array}{l}
\widehat{y}(t) \\
\widehat{x}(t)
\end{array}\right]=\left[\begin{array}{l}
C \\
I
\end{array}\right] \widehat{x}(t)+\left[\begin{array}{l}
D \\
0
\end{array}\right] u(t),
$$

where $\boldsymbol{I}$ denotes the identity matrix. The filter gain $\boldsymbol{L}$ is calculated by solving the algebraic Riccati equation by the following form

$$
L=\left(P C^{T}+\bar{N}\right) \bar{R}^{-1},
$$

where the following equation are taken and $\boldsymbol{P}$ solves the corresponding algebraic Riccati equation:

$$
\left\{\begin{array}{c}
\bar{R}=R+H N+N^{T} H^{T}+H Q H^{T} \\
\bar{N}=G\left(Q H^{T}+N\right) .
\end{array}\right.
$$

\subsection{The PWPF-CA Realization}

The PWPF with the known parameters, including $K_{p w}, T_{p w}$ and $h_{p w}=U_{o n}-U_{o f f}$ as the gain, the time constant and the hysteresis, respectively, are designed to deal with the on-off reaction thrusters. The $C A$ is also designed to deal with the overactuated system under control. Now, the low-high three-axis control torques in line with a set of $N_{L}=\frac{1}{2} N_{H}=4$ low and high thrusters could clearly be resulted as [19]

$$
\begin{aligned}
& \left\{\begin{array}{l}
M_{x L}=-P_{T}\left(T_{3 L}-T_{4 L}\right) \\
M_{y L}=-P_{T}\left(T_{1 L}-T_{2 L}\right) \\
M_{z L}=Q_{T}\left(T_{3 L}-T_{4 L}\right),
\end{array}\right. \\
& \left\{\begin{array}{c}
M_{x H}=-P_{T}\left(T_{5 H}+T_{6 H}-T_{7 H}-T_{8 H}\right) \\
M_{y H}=P_{T}\left(T_{3 H}-T_{1 H}\right)+Q_{T}\left(T_{6 H}-T_{8 H}\right) \\
M_{z H}=P_{T}\left(T_{2 H}-T_{4 H}\right)+Q_{T}\left(T_{5 H}-T_{7 H}\right),
\end{array}\right.
\end{aligned}
$$

where $T_{i L}, i=1,2, \ldots, N_{L}$, denotes the $i^{\text {th }}$ low level thrusters and $T_{i H}, i=1,2, \ldots, N_{H}$, denotes the $i^{t h}$ high level thrusters. Furthermore, $P_{T}$ and $Q_{T}$ are taken as the physical parameters of the thruster's positions. Due to the fact that $T_{i L}$ and $T_{i H}$, presented in Eqs. (18)(19), are in need of binary information, a relay, i.e. $f_{\text {on } / \text { off }}$ has to be realized to cope with $\tau_{x L H}, \tau_{y L H}$ and $\tau_{z L H}$ in the form of its effective ones, i.e. $\tau_{x_{e} L H}, \tau_{y_{e} L H}$ and $\tau_{z_{e} L H}$ by the following form

$$
\left[\begin{array}{l}
\tau_{x_{e} L H} \\
\tau_{y_{e} L H} \\
\tau_{z_{e} L H}
\end{array}\right]=E f_{\text {on/off }}\left(E^{+}\left[\begin{array}{c}
\tau_{x L H} \\
\tau_{y L H} \\
\tau_{z L H}
\end{array}\right]\right) .
$$

\subsection{The SDRE Control Benchmark}

The overall performances of the proposed control strategy are considered with respect to the $S D R E$, as the well-known optimal control approach. To formulate the present benchmark regarding the proposed control strategy, the state space model can first be presented by [17-18]

$$
\dot{x}(t)_{6 \times 1}=A_{6 \times 6} x(t)_{6 \times 1}+B_{6 \times 6} u_{S D R E}(t)_{6 \times 1},
$$

where $A$ is taken as the first part of Eq. (7) whereas the $B, x(t)$ and the $u_{S D R E}(t)$ are all taken as

$$
B=\left[\begin{array}{ll}
I_{x, y, z}^{-1} & 0_{3 \times 3} \\
\mathbf{0}_{3 \times 3} & \mathbf{0}_{3 \times 3}
\end{array}\right],
$$

$$
\boldsymbol{x}(\boldsymbol{t})=\left[\begin{array}{c}
\boldsymbol{\omega}_{\boldsymbol{s x}, \boldsymbol{y}, \mathbf{z}}(\boldsymbol{t}) \\
\varphi_{s}(t) \\
\theta_{s}(t) \\
\psi_{s}(t)
\end{array}\right],
$$

$$
u_{S D R E}(t)=\left[\begin{array}{c}
M_{x, y, z}(t) \\
0_{3 \times 1}
\end{array}\right] .
$$

The $\boldsymbol{u}_{\text {SDRE }}(t)$ is designed to minimize the following performance indices via Eq. (26)

$$
\left\{\begin{array}{l}
J_{x}(\boldsymbol{x}(\boldsymbol{t}), \boldsymbol{u}(\boldsymbol{t}))=\int_{0}^{T_{\text {sim }}} \boldsymbol{x}^{T}(\boldsymbol{t}) \boldsymbol{Q}(\boldsymbol{x}(\boldsymbol{t})) \boldsymbol{x}(\boldsymbol{t}) d t \\
J_{u}(\boldsymbol{x}(\boldsymbol{t}), \boldsymbol{u}(\boldsymbol{t}))=\int_{0}^{T_{\text {sim }}} \boldsymbol{u}^{T}(\boldsymbol{t}) \boldsymbol{R}(\boldsymbol{x}(\boldsymbol{t})) \boldsymbol{u}(\boldsymbol{t}) d t,
\end{array}\right.
$$

$$
u_{S D R E}(t)=-R^{-1}(x(t)) B^{T}(x(t)) P(x(t)) x(t),
$$

where $\boldsymbol{P}(x(t))$ can be calculated through the following Riccati Equation: 


$$
\begin{aligned}
& P(x(t)) A(x(t))+A^{T}(x(t)) P(x(t))+Q(x(t))- \\
& P(x(t)) B(x(t)) R^{-1}(x(t)) B^{T}(x(t)) P(x(t))=0
\end{aligned}
$$

\section{The Simulation Results}

The proposed control strategy is carried out through a series of experiments to be evaluated based upon the variations of the low-high thrusts levels in connection with a number of iterations in the Monte-Carlo method for the parameters $K_{C}, K_{F}$ and $K_{D}$, in its specific span. There are four cases to consider the approach performance, as tabulated in Table 1, where the acquired outcomes are only illustrated in a number of the uncertainties parameters that are randomly chosen to be concise.

\section{Table 1}

The cases carried out for the proposed control strategy

\begin{tabular}{l|l|l|l}
\hline Cases & L. H. - thrusts levels & Un. Parametrs \\
\hline 1 & Cases I & $\left\{\begin{array}{l}T_{H}=500 N \\
T_{L}=75 N\end{array}\right.$ & $\left\{\begin{array}{l}K_{C}=0.988 \\
K_{F}=1.190 \\
K_{D}=1.116\end{array}\right.$ \\
\hline 2 & Cases II & $\left\{\begin{array}{l}T_{H}=475 N \\
T_{L}=100 N\end{array}\right.$ & $\left\{\begin{array}{l}K_{C}=0.996 \\
K_{F}=1.003 \\
K_{D}=1.151\end{array}\right.$ \\
\hline 3 & Cases III & $\left\{\begin{array}{l}T_{H}=425 N \\
T_{L}=125 N\end{array}\right.$ & $\left\{\begin{array}{l}K_{C}=0.9248 \\
K_{F}=1.114 \\
K_{D}=0.9728\end{array}\right.$ \\
\hline 4 & Cases IV & $\left\{\begin{array}{l}T_{H}=400 N \\
T_{L}=150 N\end{array}\right.$ & $\left\{\begin{array}{l}K_{C}=0.916 \\
K_{F}=1.052 \\
K_{D}=1.053\end{array}\right.$ \\
\hline &
\end{tabular}

The initial parameters of the proposed strategy are tabulated in Table 2. It is to note that the coefficients of the Contl $l_{L H}, R F_{L H}$ and also $P W P F-C A_{L H}$ are all carefully tuned via MATLAB optimization toolbox.

Moreover, the moments of inertial of the space system under control are varied with time in all cases of Table 1, as illustrated in Fig. 2.

In the experiments, the initial attitudes and initial angular rates of the space system are taken as
Table 2

\begin{tabular}{|c|c|c|}
\hline & The parameters & The values \\
\hline 1 & $N_{L, H}$ & {$[4,8]$} \\
\hline 2 & $T_{L, H}$ & {$[75-150,400-500] N$} \\
\hline \multirow[t]{2}{*}{3} & \multirow{2}{*}{ Contl $_{L H}$} & $\left\{\begin{array}{l}k_{i x L}=20.0 \\
k_{i y L}=25.8 ; \\
k_{i z L}=14.7\end{array}\left\{\begin{array}{c}k_{d x L}=52.4 \\
k_{d y L}=427.0 ; \\
k_{d z L}=430.0\end{array} ;\left\{\begin{array}{c}k_{p x L}=8.4 \\
k_{p y L}=72.2 \\
k_{p z L}=72.2\end{array}\right.\right.\right.$ \\
\hline & & $\left\{\begin{array}{c}k_{i x H}=0 \\
k_{i y H}=25.8 \\
k_{i z H}=14.6\end{array} ;\left\{\begin{array}{l}k_{d x H}=0 \\
k_{d y H}=0 \\
k_{d z H}=0\end{array} ;\left\{\begin{array}{c}k_{p x H}=0 \\
k_{p y H}=30.0 \\
k_{p z H}=48.8\end{array}\right.\right.\right.$ \\
\hline \multirow[t]{2}{*}{4} & \multirow[b]{2}{*}{$R F_{L H}$} & $k_{p x L}=15.0$ \\
\hline & & $\left\{\begin{array}{c}k_{p x H}=0 \\
k_{p y H}=61.0 \\
k_{p z H}=50.0\end{array}\right.$ \\
\hline \multirow[t]{2}{*}{5} & \multirow[t]{2}{*}{$P W P F-C A_{L H}$} & $\left\{\begin{array}{c}K_{x y z}=55 \\
\tau_{x y z}=0.15 \\
U_{o n}=0.8 \\
U_{o f f}=0.1\end{array}\right.$ \\
\hline & & $P_{T}=0.4, Q_{T}=0.6 \mathrm{~m}$ \\
\hline 6 & $f_{\text {on } / o f f}$ & 0.1 \\
\hline \multirow[t]{2}{*}{7} & \multirow{2}{*}{ Noise } & $\left\{\begin{array}{c}\operatorname{mean}_{p r}=0 \\
\operatorname{Cov}_{p r}=1\end{array}\right.$ \\
\hline & & $\left\{\begin{array}{c}\operatorname{mean}_{m t}=0 \\
\operatorname{Cov}_{m t}=1\end{array}\right.$ \\
\hline 8 & Estimator & $Q=10 ; R=1 ; N=0$ \\
\hline 9 & Engine Pos. & {$[-0.1,0,0]$} \\
\hline & $\begin{array}{l}s 0=0^{\circ} \\
=-2^{\circ} \\
=10^{\circ}\end{array}$ & (28) \\
\hline
\end{tabular}

The initial parameters of the proposed control strategy

$\left\{\begin{array}{l}\omega_{s x}=0.05 \% s \\ \omega_{s y}=0.10 \% / s \\ \omega_{s z}=0.15 \% .\end{array}\right.$

Moreover, the referenced commands are taken as

$$
\left\{\begin{array}{c}
\varphi_{r}=0^{\circ} \\
\theta_{r}=-4^{\circ} \\
\psi_{r}=8^{\circ} .
\end{array}\right.
$$


Figure 2

The moments of inertial

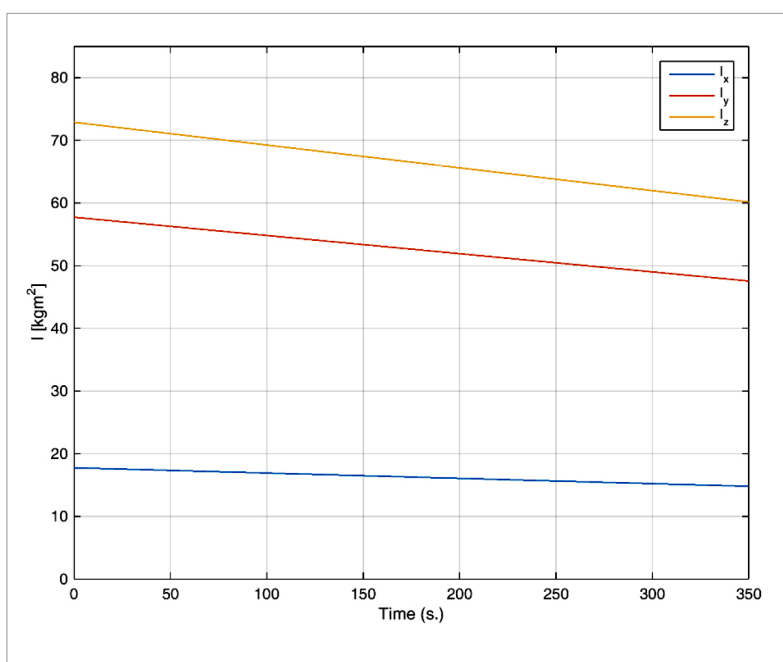

\subsection{The First Experiment}

The first experiment is carried out regarding the Case $I$ of Table 1 . The variations of the parameters of $K_{O} K_{F}$ and $K_{D}$ are taken in the span of $0.90-1.2$ in the fifteen iterations, as illustrated in Fig. 3, to provide a band of the parameters uncertainties and disturbances through the variations of thrust vectors and center of mass, as illustrated in Fig. 4.

The investigated outcome of the proposed control strategy in the first experiment is acquired based upon the system, noisy and estimated three-axis rotational angles and the corresponding rates in the specific value of the parameters uncertainties of Table 1 , as illustrated in Fig. 5. Subsequently, the absolute errors of the noisy and the related estimated rotational angles and their rates are correspondingly illustrated in Fig. 6.

\section{Figure 3}

The parameters of $K_{C}, K_{F}$ and $K_{D}$ - case I

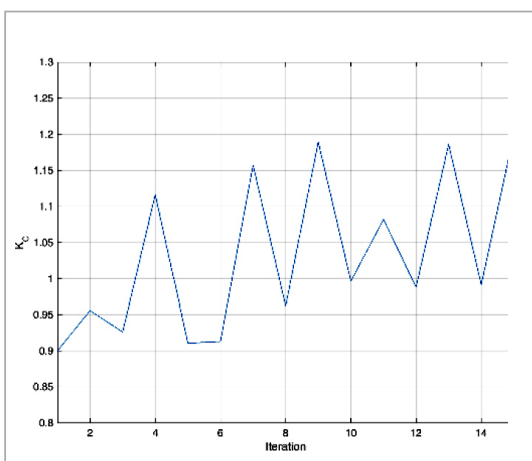

a

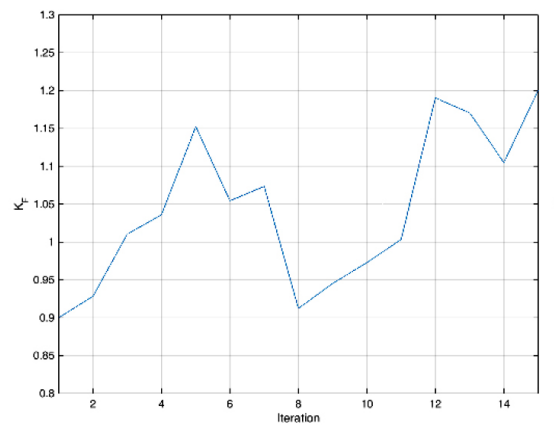

b

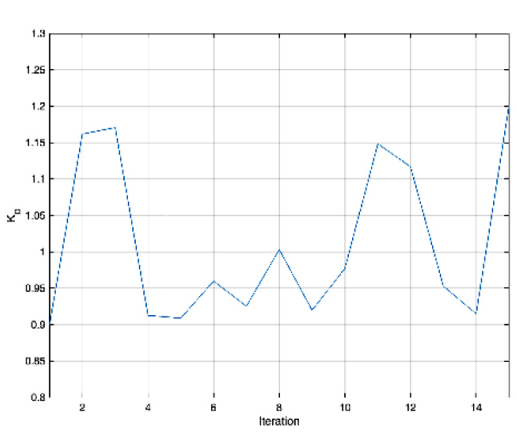

C

\section{Figure 4}

The parameters of $F, D$ and $L$ - case I

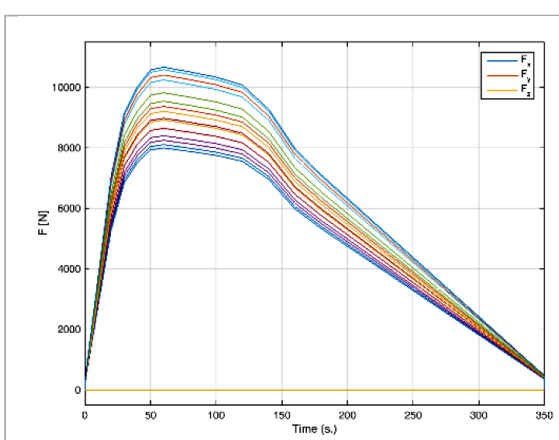

a

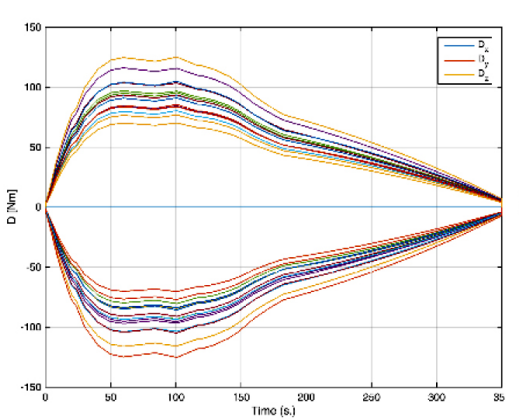

$\mathrm{b}$

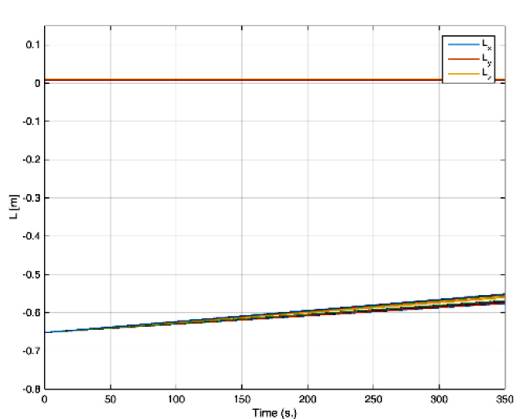

c 
Figure 5

The three-axis system, noisy and estimated angular rotations (a)-(c), angular rates (d)-(f)-case I
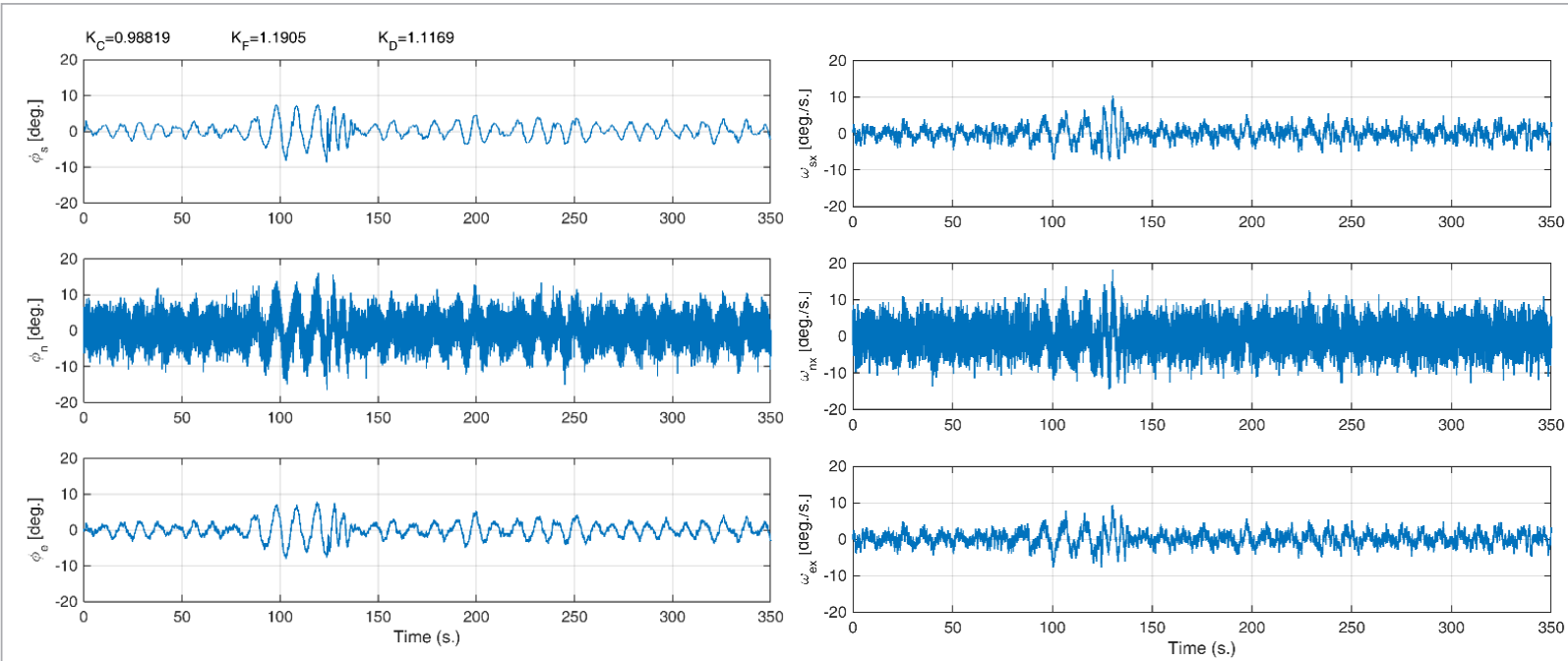

a

d
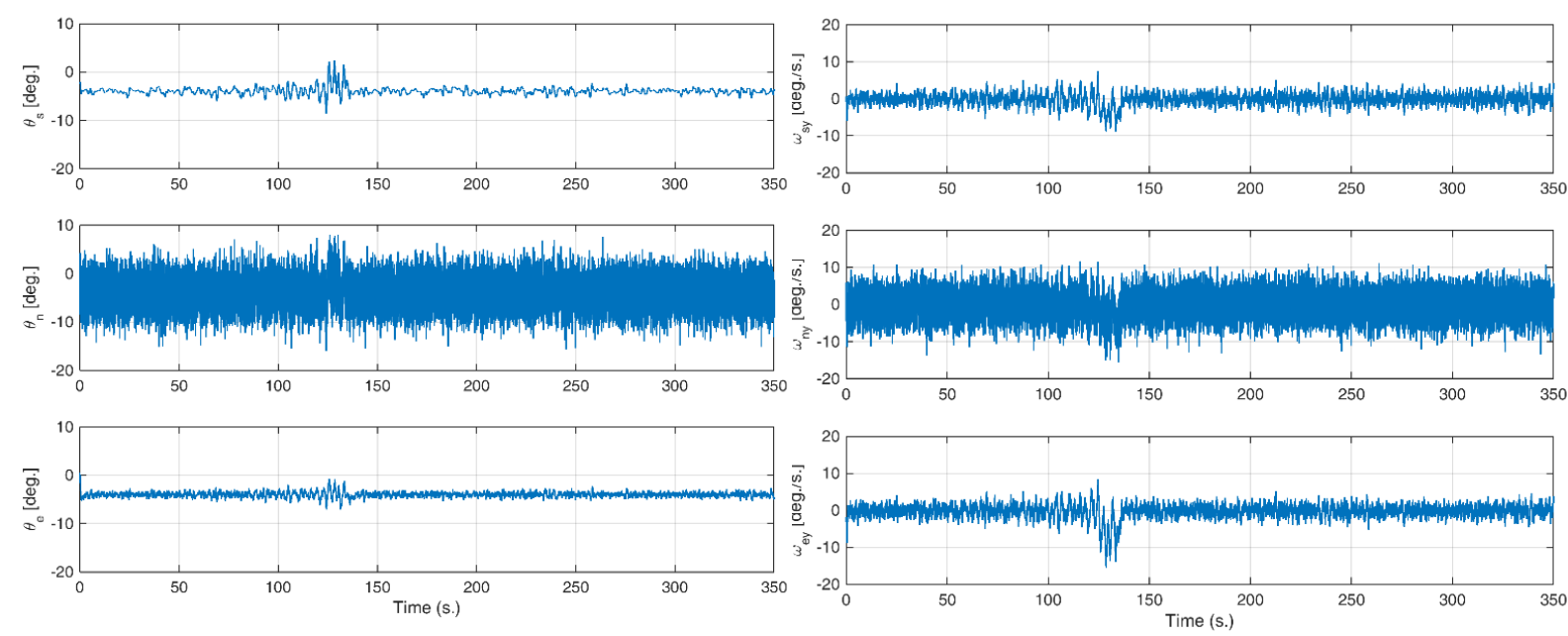

b
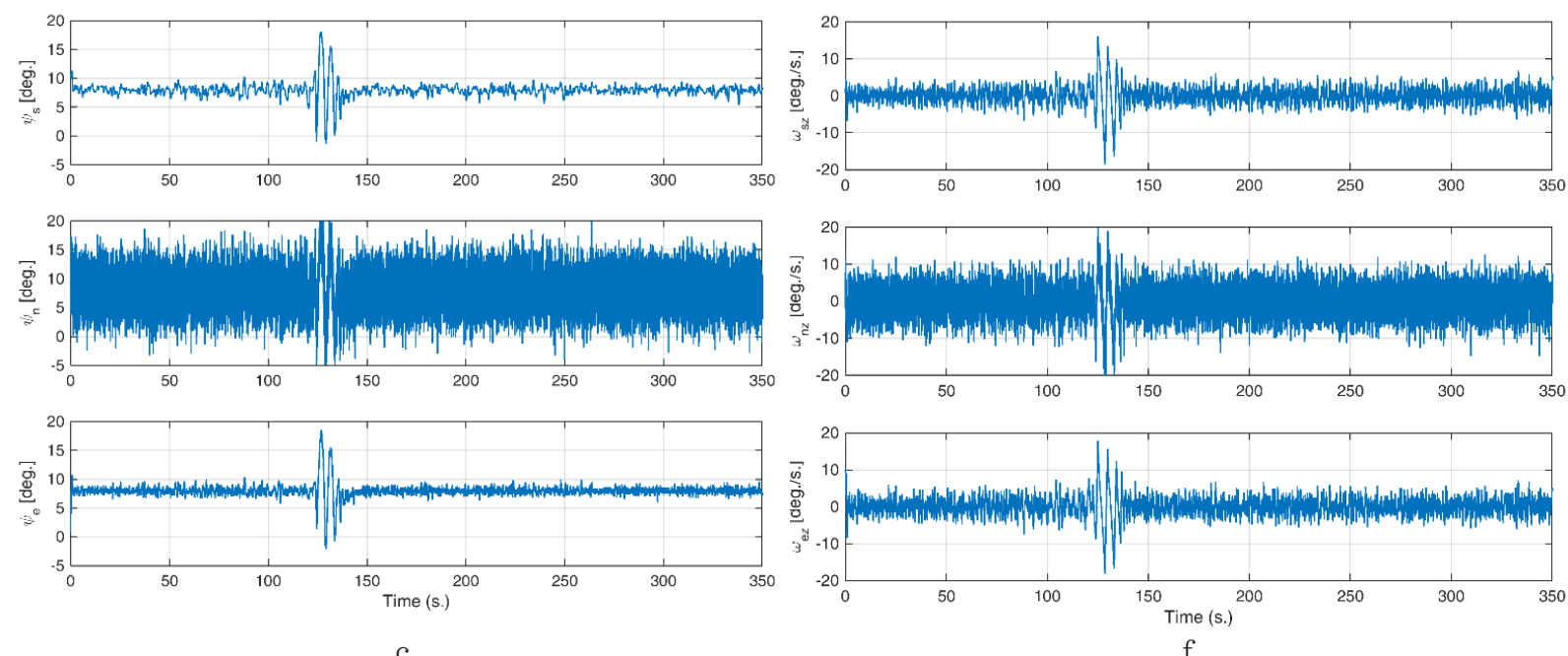
Figure 6

The three-axis estimated angular rotations errors (a)-(c), angular rates errors (d)-(f)-case I
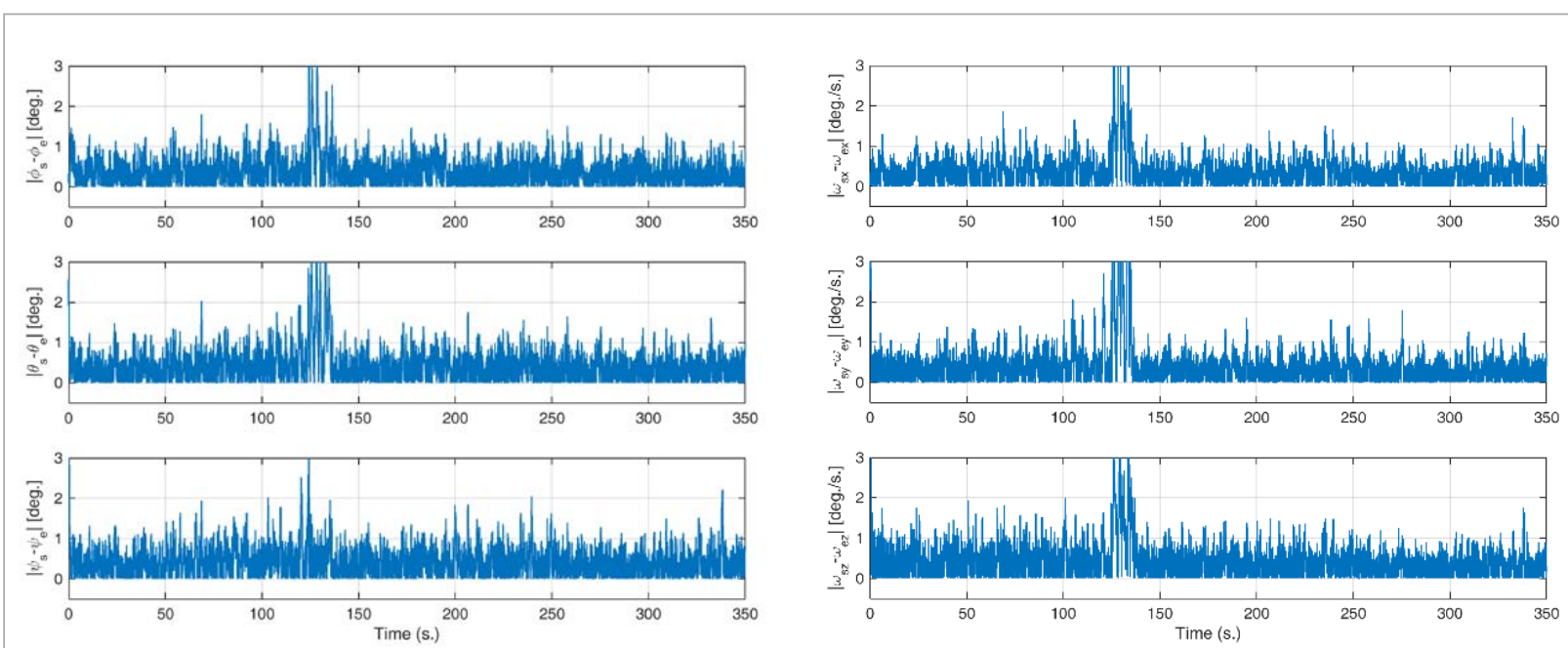

a

\subsection{The Second Experiment}

The second experiment is carried out regarding the Case II of Table 1. The variations of the parameters of $K_{C}, K_{F}$ and $K_{D}$ are taken in the span of 0.90-1.2 in the fifteen iterations, as illustrated in Fig. 7, to provide a band of the parameters uncertainties and disturbances through the variations of thrust vectors and center of mass, as illustrated in Fig. 8.

The investigated outcome of the proposed control

strategy in the second experiment is acquired based upon the system, noisy and estimated three-axis rotational angles and the corresponding rates in the specific value of the parameters uncertainties of Table 1, as illustrated in Fig. 9. Subsequently, the absolute errors of the noisy and the related estimated rotational angles and their rates are correspondingly illustrated in Fig. 10.

\section{Figure 7}

The parameters of $K_{C}, K_{F}$ and $K_{D}$ - case II

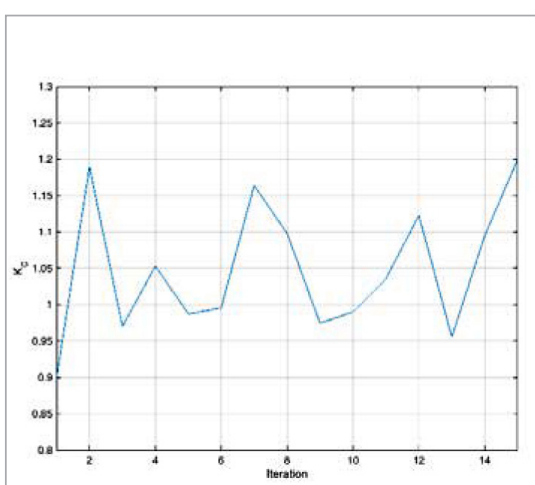

a

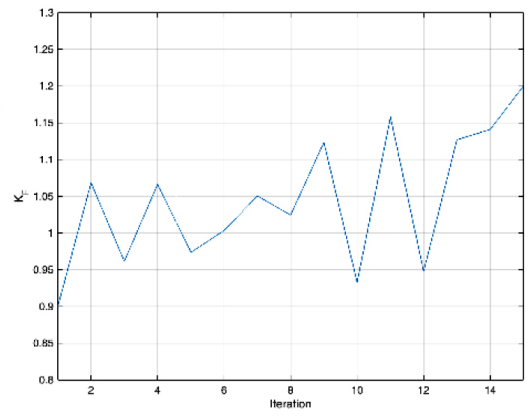

$\mathrm{b}$

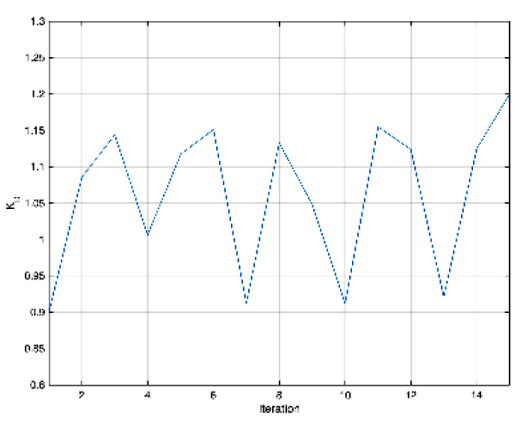

$\mathrm{c}$ 
Figure 8

The parameters of $F, D$ and $L$ - case II

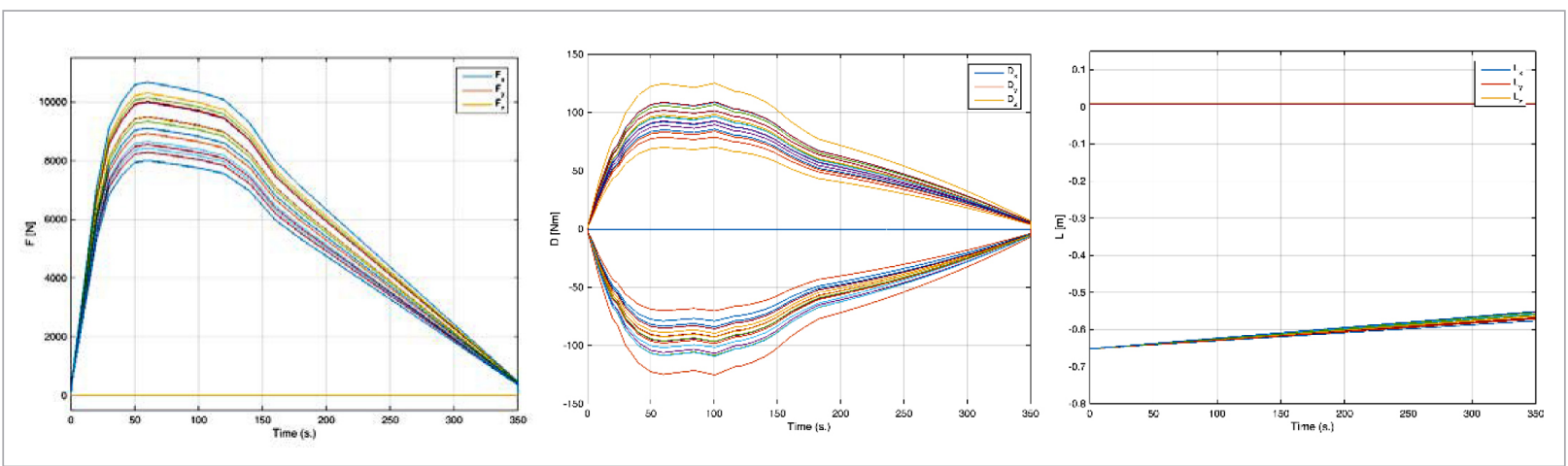

Figure 9

The three-axis system, noisy and estimated angular rotations (a)-(c), angular rates (d)-(f)-case II
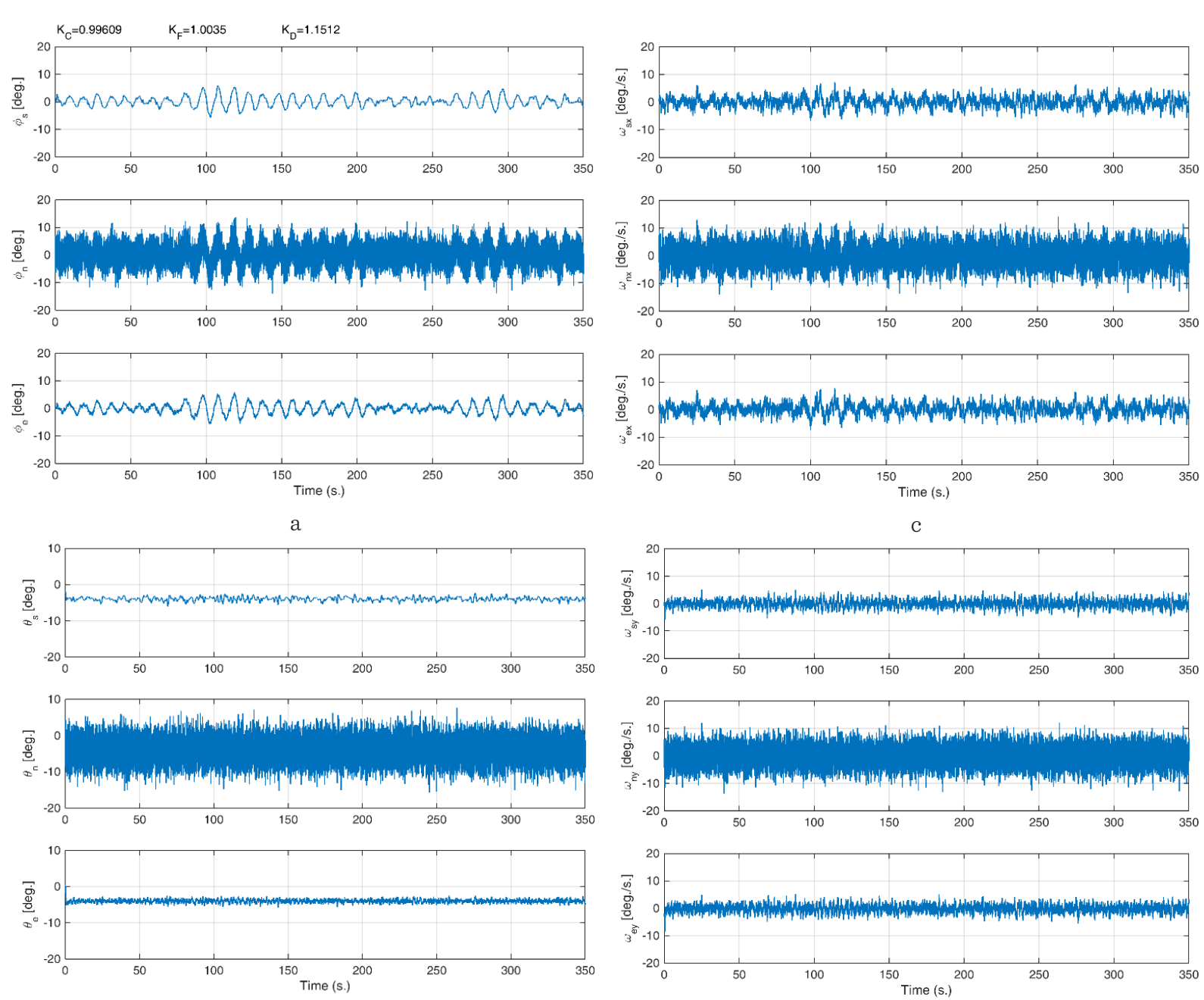

$\mathrm{b}$

d 


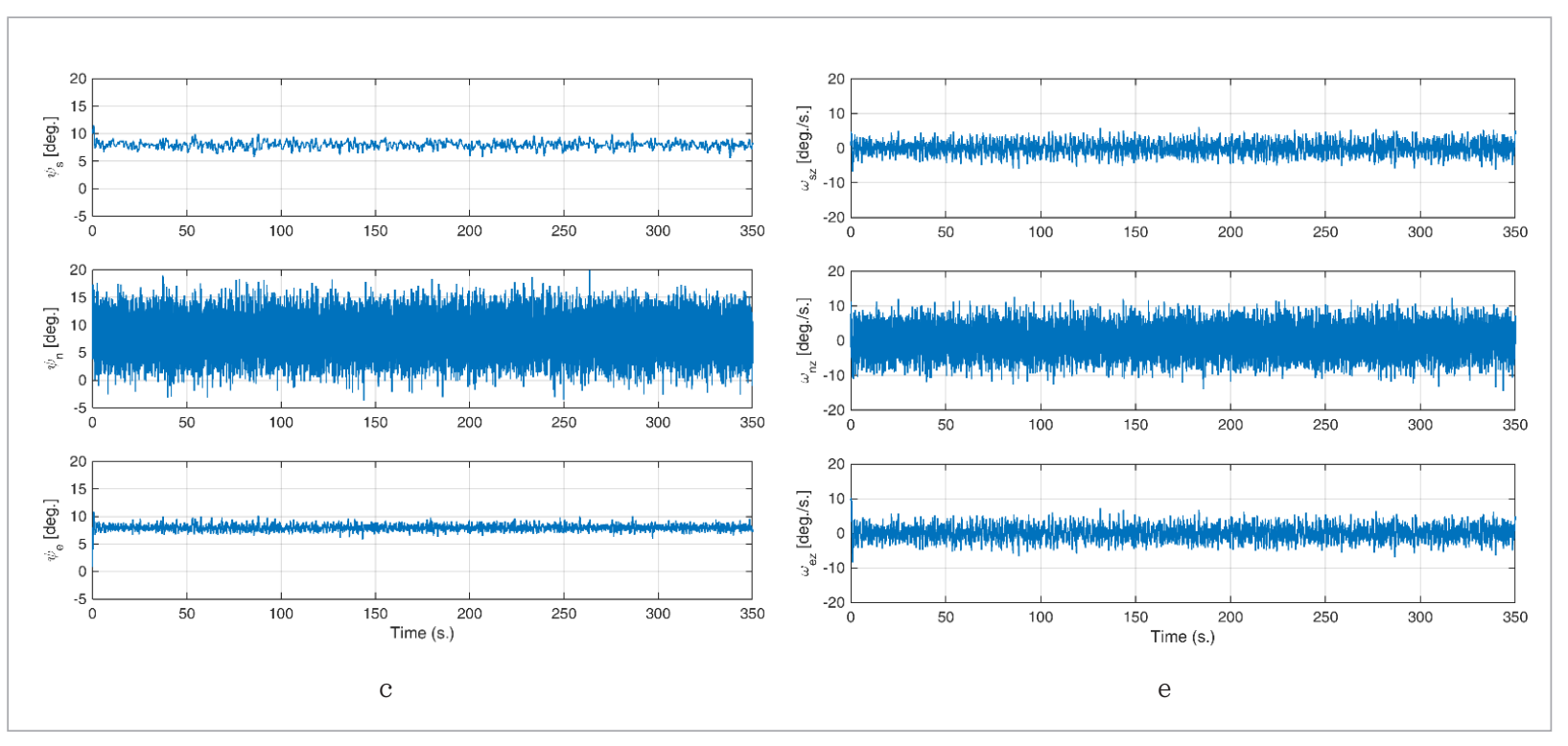

Figure 10

The three-axis estimated angular rotations errors (a)-(c), angular rates errors (d)-(f)-case II

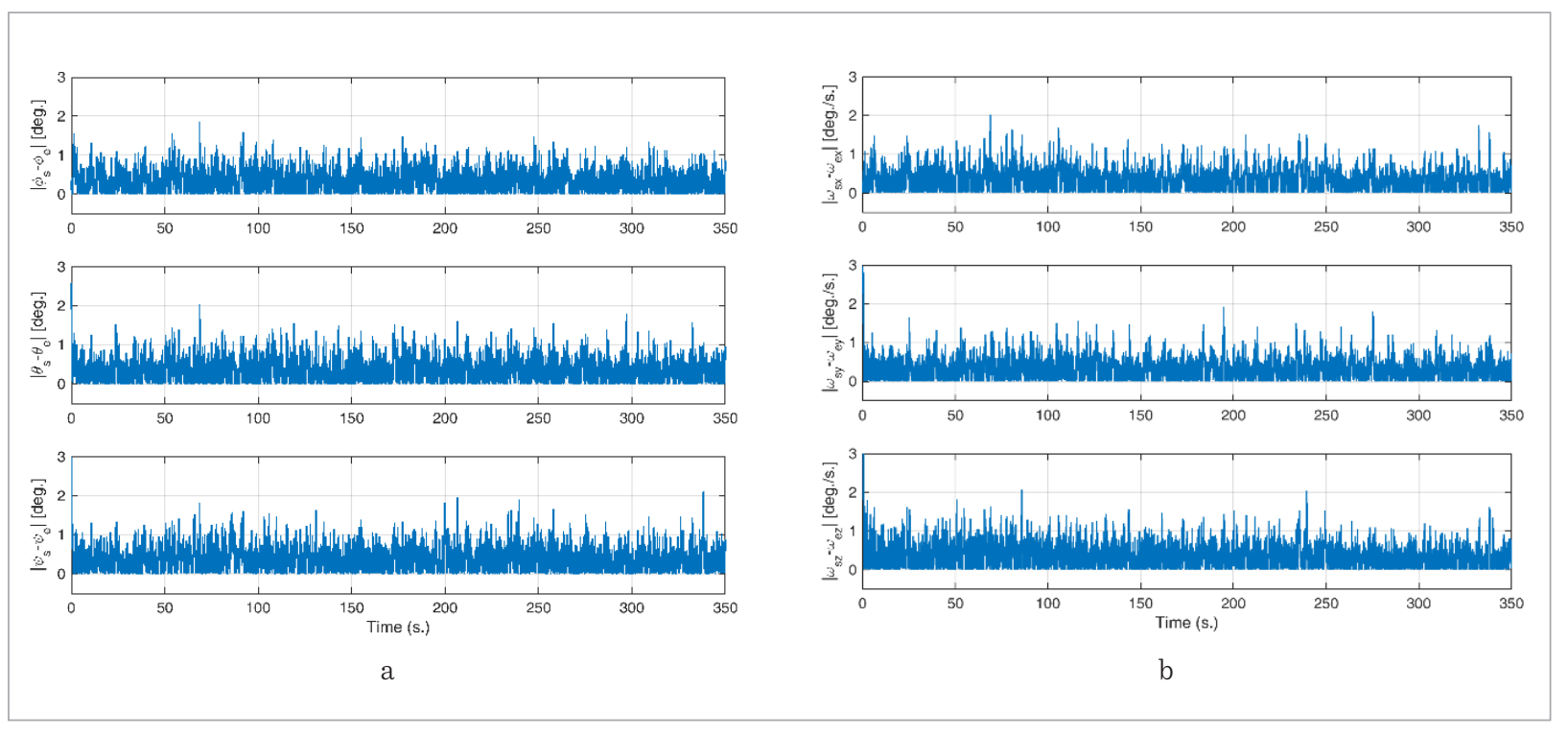

\subsection{The Third Experiment}

The third experiment is carried out regarding the Casa III of Table 1. The variations of the parameters of $K_{C}, K_{F}$ and $K_{D}$ are taken in the span of 0.90-1.2 in the fifteen iterations, as illustrated in Fig. 11 to provide a band of the parameters uncertainties and disturbances through the variations of thrust vectors and center of mass, as illustrated in Fig. 12.

The investigated outcome of the proposed control strategy in the third experiment is acquired based upon the system, noisy and estimated three-axis rotational angles and the corresponding rates in the specific value of the parameters uncertainties of Table 1, as illustrated in Fig. 13. Subsequently, the absolute errors of the noisy and the related estimated rotational angles and their rates are correspondingly illustrated in Fig. 14. 


\section{Figure 11}

The parameters of $K_{C}, K_{F}$ and $K_{D}$ - case III

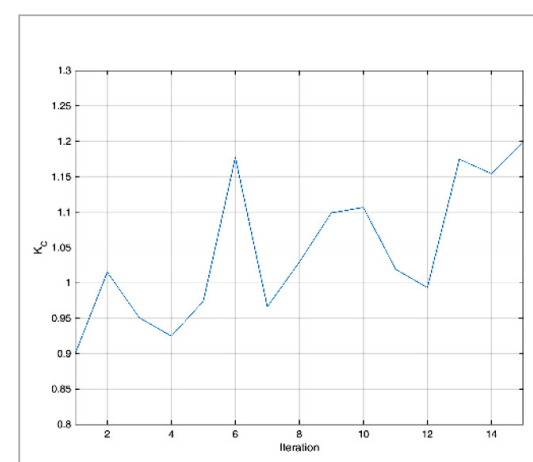

a

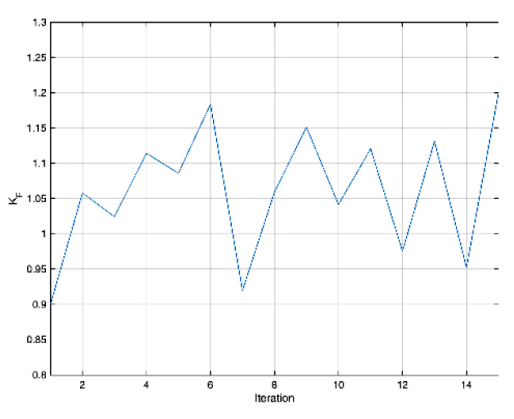

b

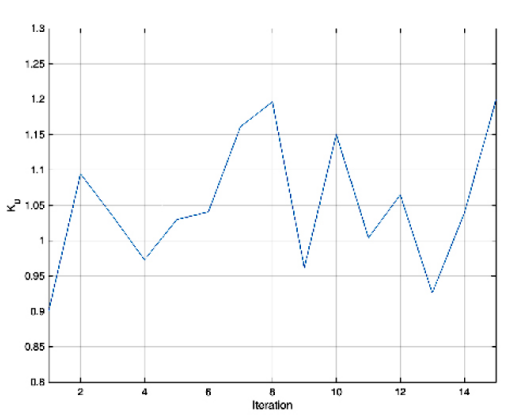

C

\section{Figure 12}

The parameters of $F, D$ and $L$ - case III

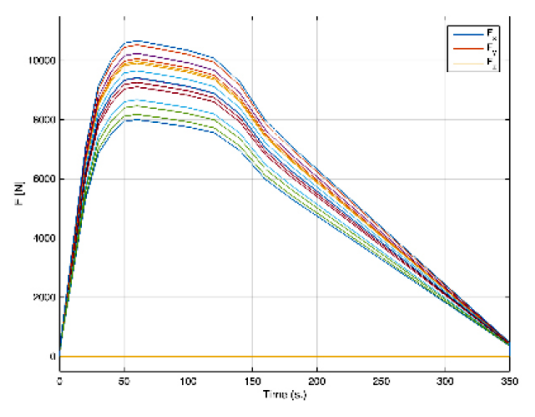

a

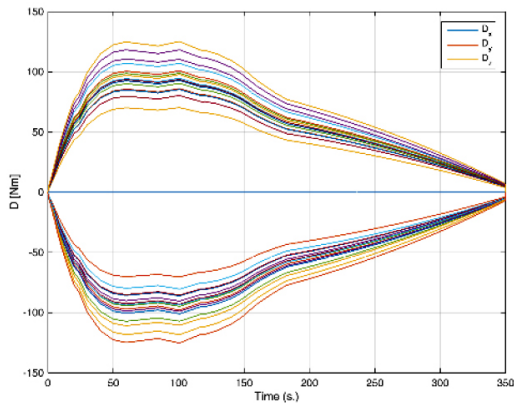

b

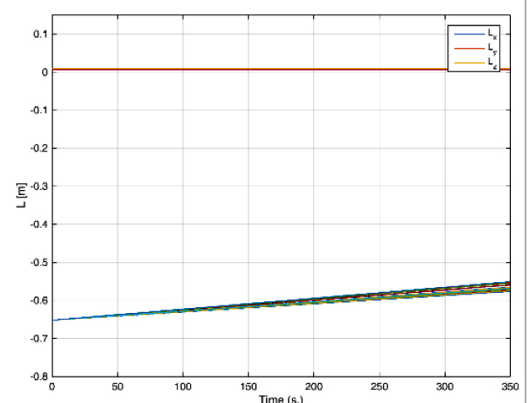

\section{Figure 13}

The three-axis system, noisy and estimated angular rotations (a)-(c), angular rates (d)-(f)-case III
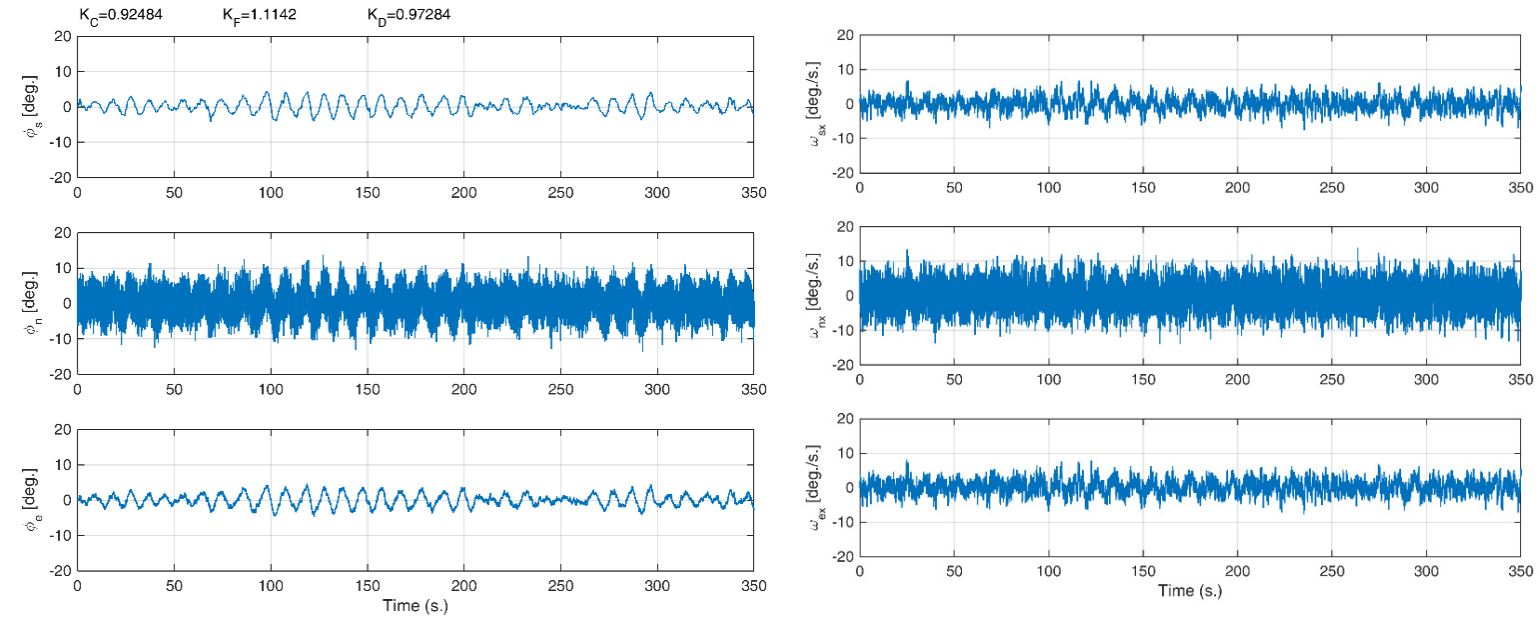

a 


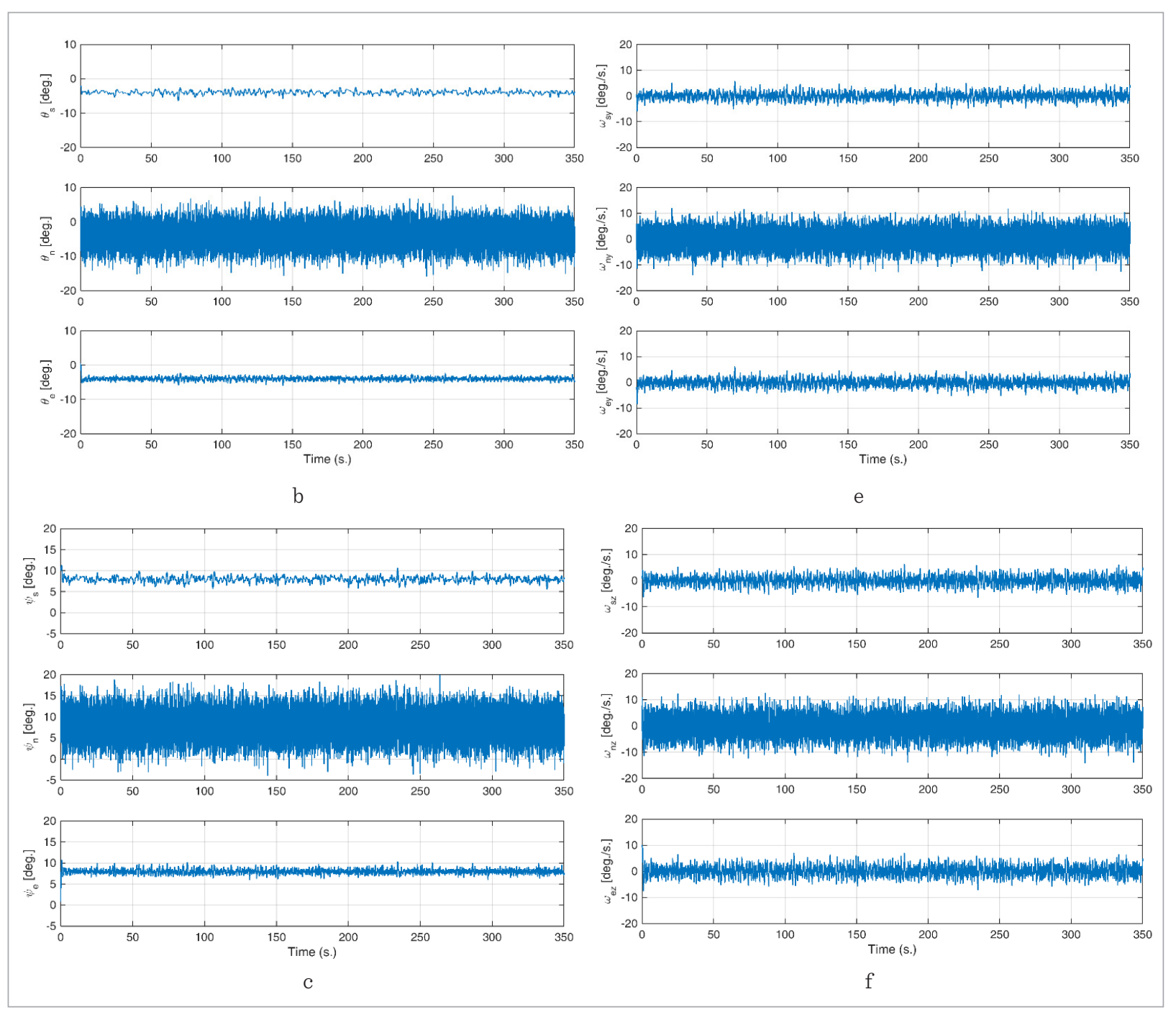

Figure 14

The three-axis estimated angular rotations errors (a)-(c), angular rates errors (d)-(f)-case III

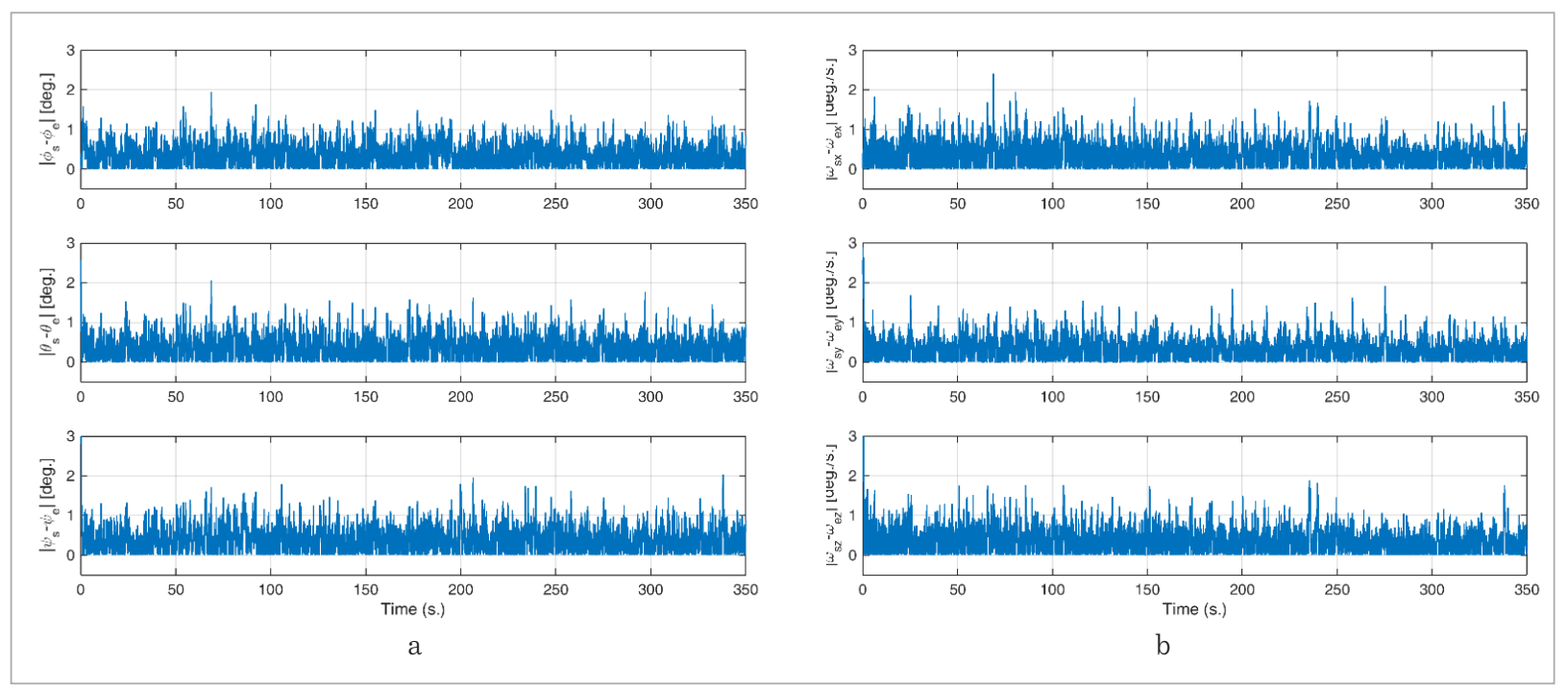




\subsection{The Fourth Experiment}

The last experiment is carried out regarding the Case $I V$ of Table 1 . The variations of the parameters of $K_{C}$, $K_{F}$ and $K_{D}$ are taken in the span of 0.90-1.2 in the fifteen iterations, as illustrated in Fig. 15, to provide a band of the parameters uncertainties and disturbances through the variations of thrust vectors and center of mass, as illustrated in Fig. 16.

\section{Figure 15}

The parameters of $K_{C}, K_{F}$ and $K_{D}$-case IV

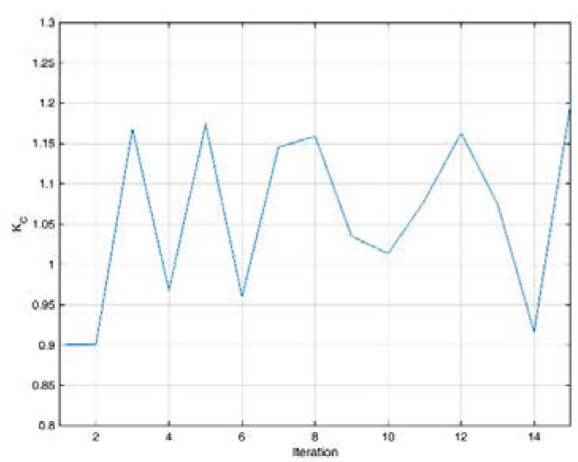

a

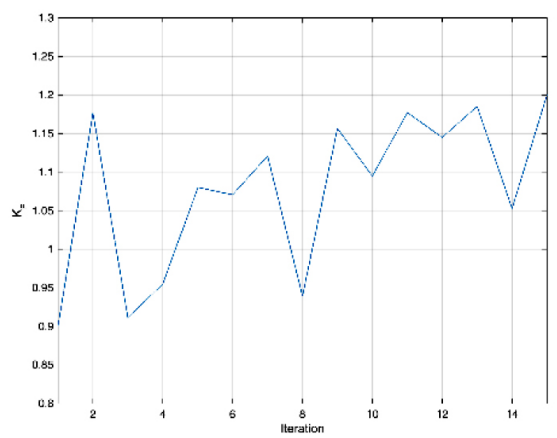

b

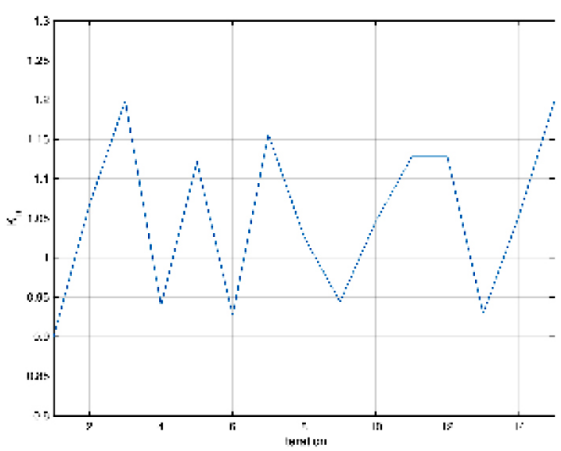

c
The investigated outcome of the proposed control strategy in the last experiment is acquired based upon the system, noisy and estimated three-axis rotational angles and the corresponding rates in the specific value of the parameters uncertainties of Table 1, as illustrated in Fig. 17. Subsequently, the absolute errors of the noisy and the related estimated rotational angles and their rates are correspondingly illustrated in Fig. 18.

\section{Figure 16}

The parameters of $F, D$ and $L$-case IV

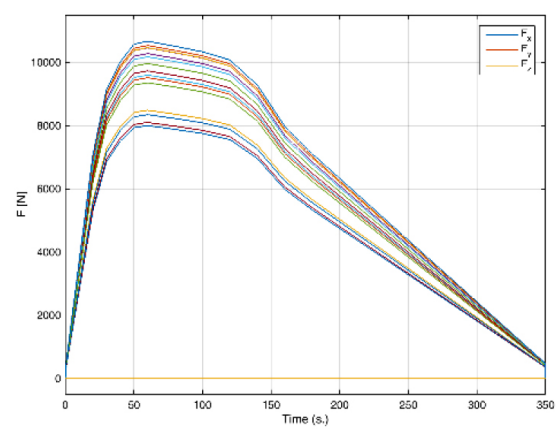

a

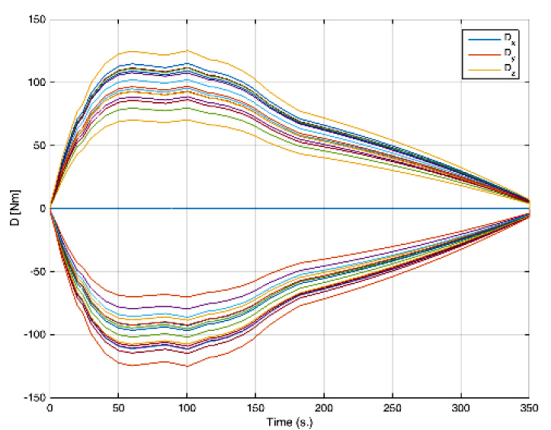

b

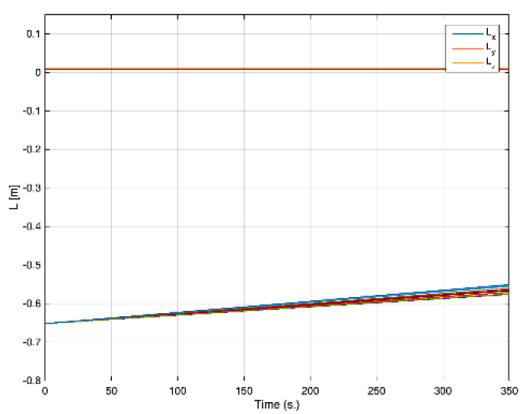

c 
Figure 17

The three-axis system, noisy and estimated angular rotations (a)-(c), angular rates (d)-(f)-case IV
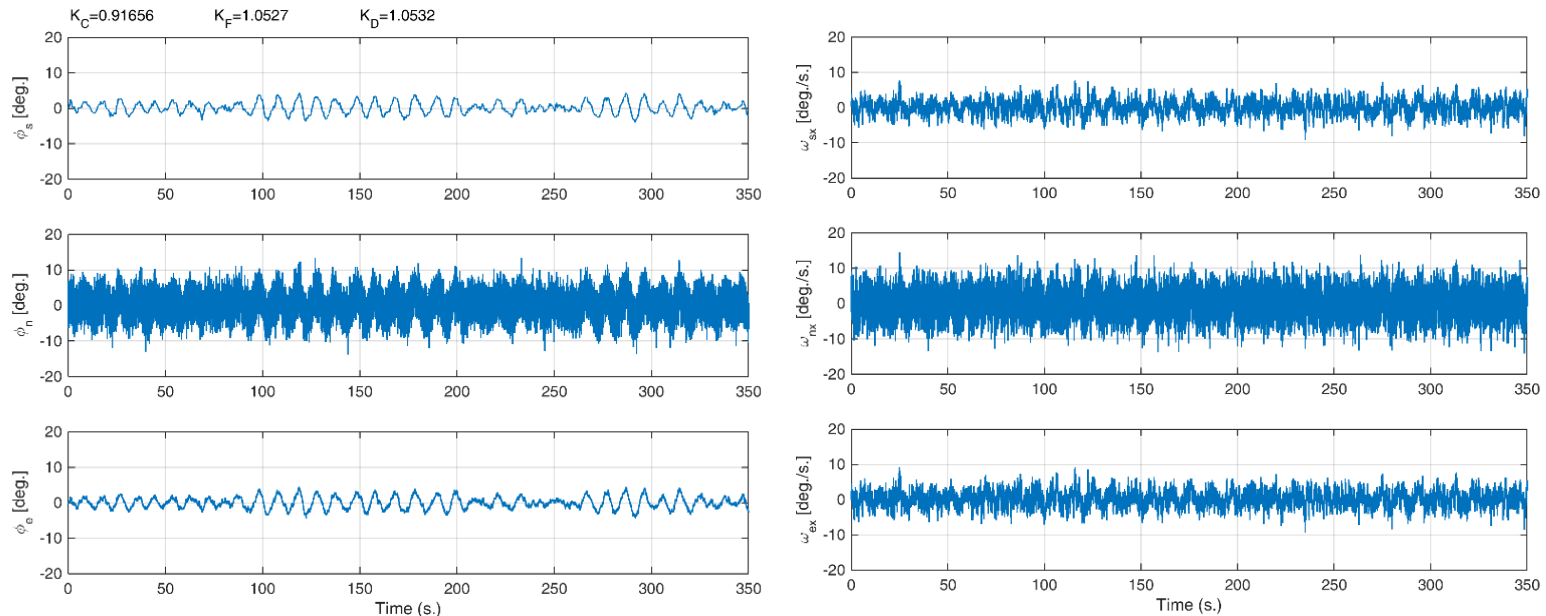

a

d
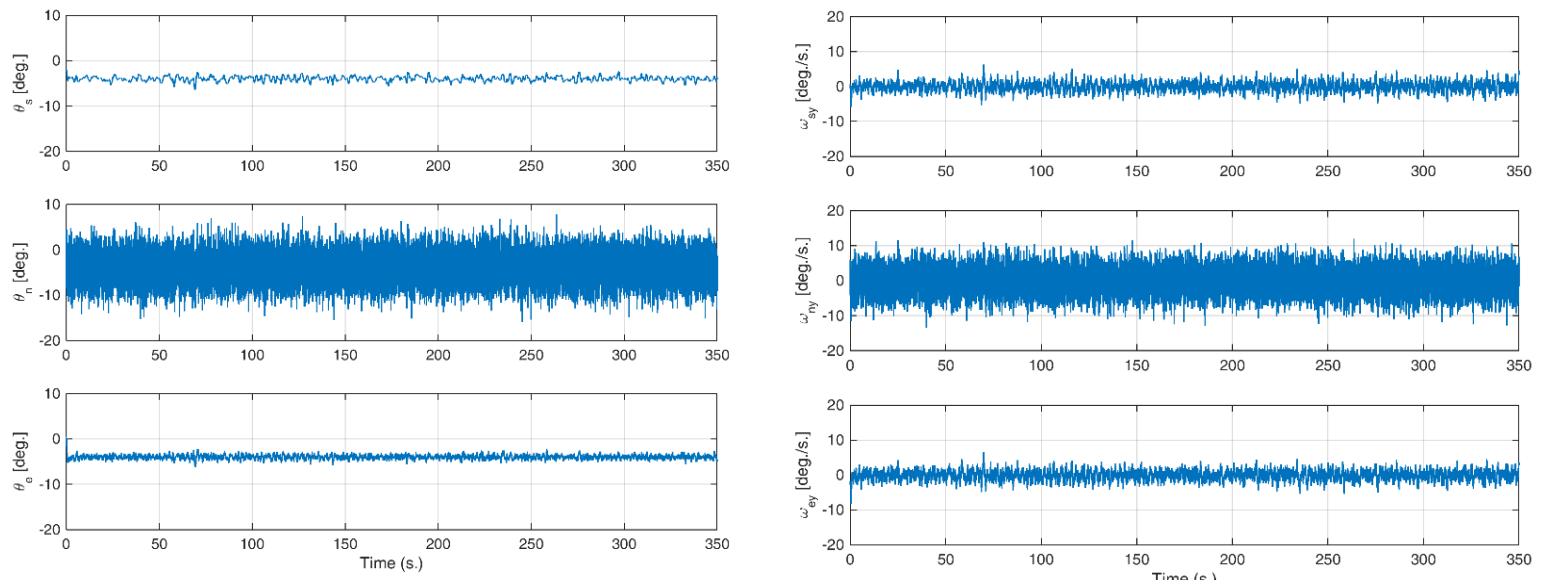

b

e
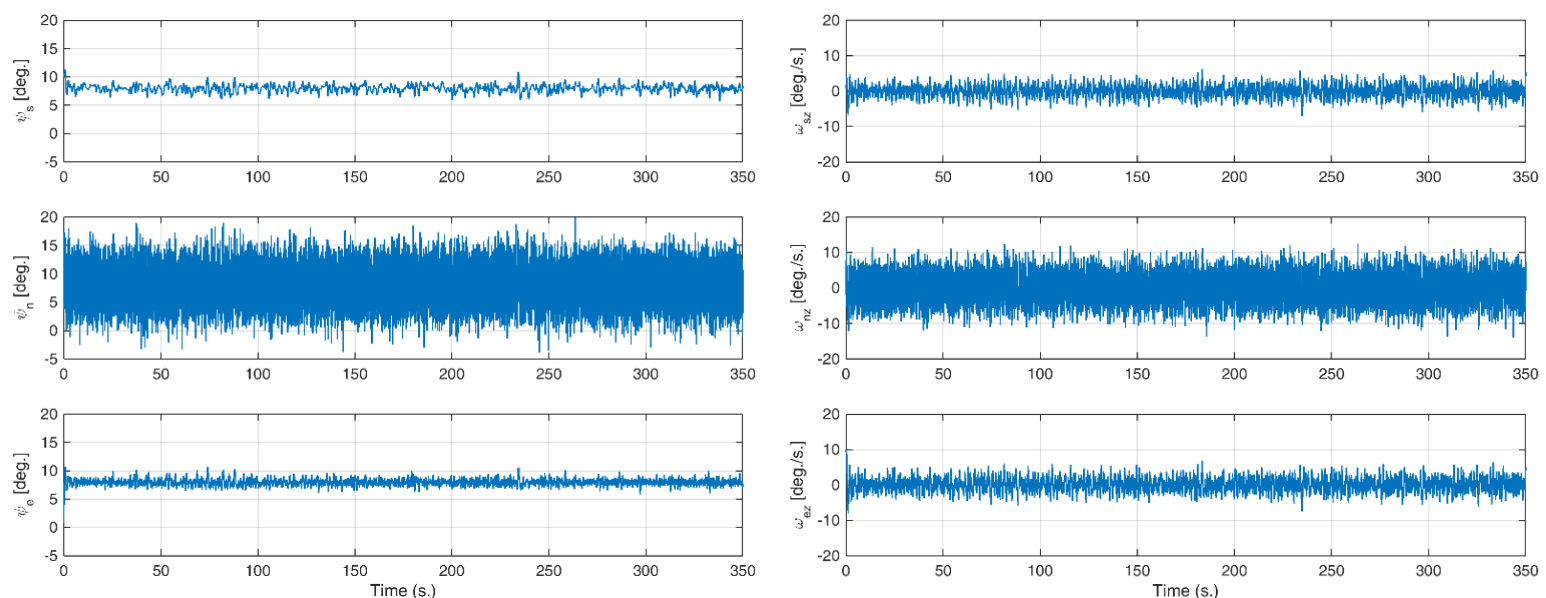


\section{Figure 18}

The three-axis estimated angular rotations errors (a)-(c), angular rates errors (d)-(f)-case IV
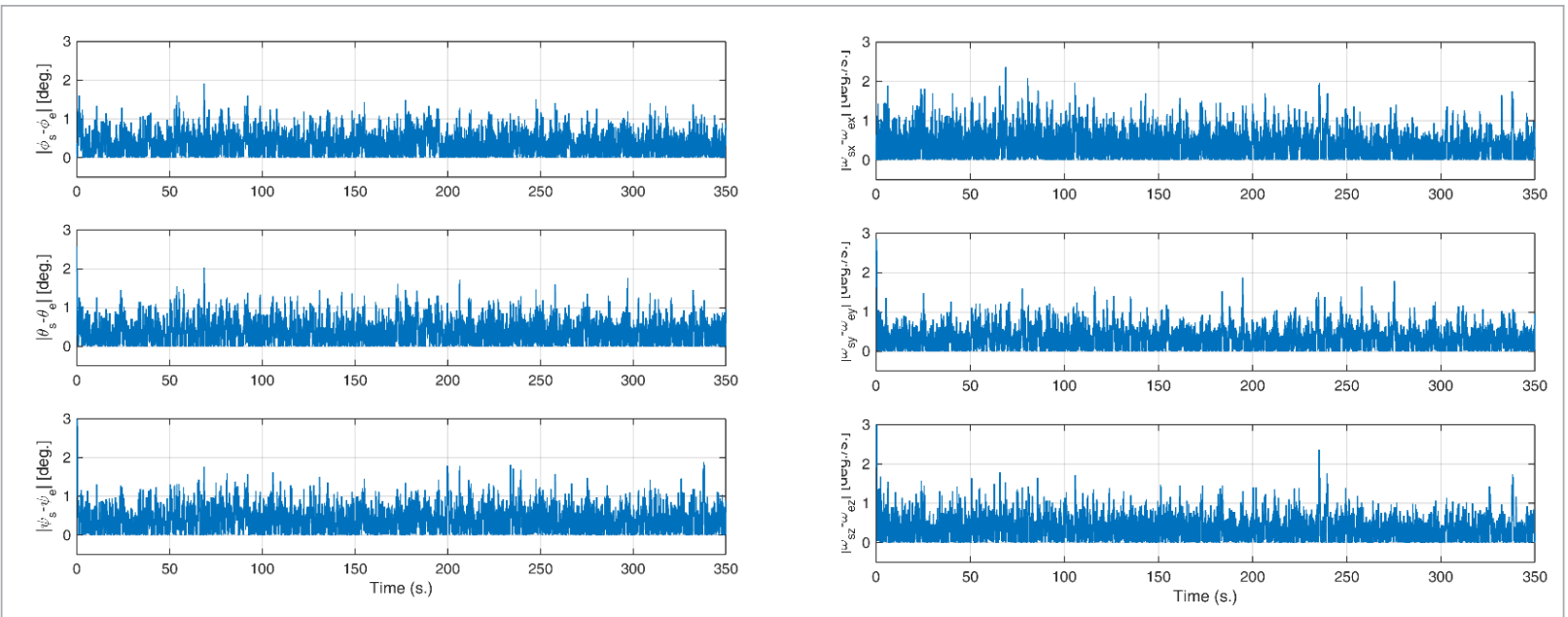

a

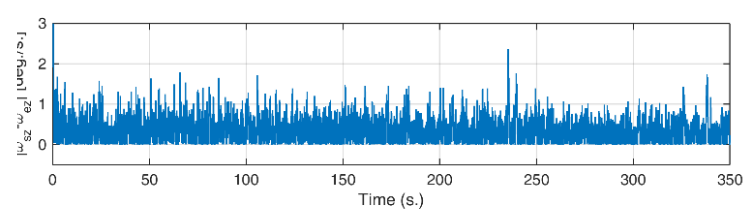

b

\subsection{The Verification of the Strategy}

The verification of the strategy proposed here is just considered through the realization of the $S D R E$ by the following parameters and a number of wellknown potential benchmarks including Zhang's benchmarks, as well:

$$
\left\{\begin{array}{c}
\varphi_{s 0}=2^{\circ}, \theta_{s 0}=-15^{\circ}, \psi_{s 0}=10^{\circ} \\
\omega_{s x 0}=\omega_{s y 0}=\omega_{s z 0}=0.5^{\circ} / \mathrm{s} \\
\boldsymbol{R}(\boldsymbol{x}(\boldsymbol{t}))=\frac{1}{2} \boldsymbol{I}_{\mathbf{6} \times \mathbf{6}},
\end{array}\right.
$$

where $\boldsymbol{I}_{6 \times 6}$ denotes the identity matrix with the dimension of six. Moreover, the following parameters are taken to carry out the present benchmark:

$$
\left\{\begin{array}{c}
T_{s i m}=350 \mathrm{~s} \\
I_{x}=25, I_{y}=85, I_{z}=75 \mathrm{kgm}^{2} \\
\varphi_{r}=\theta_{r}=\psi_{r}=0^{\circ} \\
\omega_{r x}=\omega_{r y}=\omega_{r z}=0^{\circ} / \mathrm{s} \\
\boldsymbol{Q}(\boldsymbol{x}(\boldsymbol{t}))=\boldsymbol{I}_{\mathbf{6} \times \mathbf{6}} .
\end{array}\right.
$$

Based upon the steady state errors regarding $\varphi_{s}{ }^{\circ}, \theta_{s}{ }^{\circ}, \psi_{s}{ }^{\circ}$ and $\boldsymbol{\omega}_{s x \boldsymbol{y}, \boldsymbol{z}}{ }^{\circ} / s$ and also the results of the $J(x(t), u(t))=J_{x}(x(t), u(t))+J_{u}(x(t), u(t))$, the efficiencies of the proposed control strategy can be verified in Table 3.
Table 3

The verification of the proposed control strategy in connection with the SDRE and the two potential

\begin{tabular}{|c|c|c|c|c|}
\hline & $\begin{array}{l}\text { The strategies/ } \\
\text { benchmarks }\end{array}$ & $\begin{array}{c}\text { Maximum } \\
\text { three-axis atti- } \\
\text { tude rotational } \\
\text { angles errors } \\
\text { in steady state } \\
\text { (deg.) }\end{array}$ & $\begin{array}{l}\text { Maximum } \\
\text { three-axis } \\
\text { angular rates } \\
\text { errors in } \\
\text { steady state } \\
\text { (deg./s) }\end{array}$ & 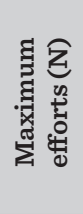 \\
\hline 1 & SDRE & 0.053 & 0.094 & 40.07 \\
\hline 2 & $\begin{array}{l}\text { He's benchmark } \\
{[11]}\end{array}$ & 0.070 & 0.070 & - \\
\hline 3 & $\begin{array}{l}\text { Zhang's } \\
\text { benchmark [32] }\end{array}$ & 0.080 & 0.040 & 100 \\
\hline 4 & $\begin{array}{l}\text { The proposed } \\
\text { strategy }\end{array}$ & 0.098 & 0.054 & 29.76 \\
\hline
\end{tabular}
benchmarks

\section{Conclusion}

A control strategy is proposed to deal with the space system in the presence of parameters uncertainties and disturbances that are provided based upon the variations of the thrust vector, center of mass, engine 
misalignment, moment of inertial and other related parameters. In the strategy proposed here, the optimal state estimator scheme is designed to deal with the system under control, while the process noise of a set of thrusters and also the measurement noise of a set of sensors are considered to be dealt with through optimal state estimator scheme to present the investigated outcomes, in a real situation. A combination of low and high thrusts levels is acquired to handle the three-axis rotational angles and their rates of the

\section{References}

1. Allende-Alba, G., Montenbruck, O. Robust and Precise Baseline Determination of Distributed Spacecraft in LEO. Advances in Space Research, 2016, 57, 46-63. https://doi.org/10.1016/j.asr.2015.09.034

2. Cpalka, K., Lapa, K., Przybyl, A. A New Approach to Design of Control Systems Using Genetic Programming. Information Technology and Control, 2015, 44(4), 433442. https://doi.org/10.5755/j01.itc.44.4.10214

3. Cheng, Y., Du, H., He, Y., Jia, R. Distributed Finite-Time Attitude Regulation for Multiple Rigid Spacecraft via Bounded Control. Information Sciences, 2016, 328, 144-157. https://doi.org/10.1016/j.ins.2015.08.042

4. Dong, H., Hu, Q., Ma, G. Dual-Quaternion Based Fault-Tolerant Control for Spacecraft Formation Flying with Finite-Time Convergence. ISA Transactions, 2016, 61, 87-94. https://doi.org/10.1016/j.isatra.2015.12.008

5. Doroshin, A. V. Hetero Clinic Chaos and Its Local Suppression in Attitude Dynamics of an Asymmetrical Dual-Spin Spacecraft and Gyrostat-Satellites. The Part I - Main Models and Solutions. Communications in Nonlinear Science and Numerical Simulation, 2016, 31, 151-170. https://doi.org/10.1016/j.cnsns.2015.06.022

6. Felicetti, L., Palmerini, G. B. Analytical and Numerical Investigations on Spacecraft Formation Control by Using Electrostatic Forces. Acta Astronautica, 2016, 123, https://doi.org/10.1016/j.actaastro.2015.12.056

7. Felicetti, L., Palmerini, G. B. Three Spacecraft Formation Control by Means of Electrostatic Forces. Aerospace Science and Technology, 2016, 48, 261-271. https://doi.org/10.1016/j.ast.2015.11.022

8. Guarnaccia, L., Bevilacqua, R., Pastorelli, S. P. Suboptimal LQR-Based Spacecraft Full Motion Control: Theo- present space system, while a band of parameters uncertainties and disturbances are generated to consider the proposed approach performance through a series of experiments in the Monte-Carlo based method. The investigated results indicate that the performance of the proposed control strategy is acceptable, as long as the state-dependent Riccati equation based on the rotational angles in accordance with the corresponding angular rates and also a number of the potential benchmarks are all considered.

ry and Experimentation. Acta Astronautica, 2016, 122, 114-136. https://doi.org/10.1016/j.actaastro.2016.01.016

9. Garmendia, I., Anglada, E., Vallejo, H., Seco, M. Accurate Calculation of Conductive Conductances in Complex Geometries for Spacecraft Thermal Models. Advances in Space Research, 2016, 57, 1087-1097. https:// doi.org/10.1016/j.asr.2015.12.027

10. Guo, Y., Song, S.-M., Li, X.-H. Finite-Time Output Feedback Attitude Coordination Control for Formation Flying Spacecraft Without Unwinding. Acta Astronautica, 2016, 122, 159-174. https://doi.org/10.1016/j.actaastro.2016.01.015

11. He, C., Jie, H. The Leader-Following Attitude Control of Multiple Rigid Spacecraft Systems. Automatica, 2014, 50(4), 1109-1115. https://doi.org/10.1016/j.automatica.2014.01.003

12. Huang, W., Xie, H., Shen, C., Li, J. A Robust Strong Tracking Cubature Kalman Filter for Spacecraft Attitude Estimation with Quaternion Constraint. Acta Astronautica, 2016, 121, 153-163. https://doi.org/10.1016/j. actaastro.2016.01.009

13. Jia, Y., Yang, X. Optimization of Control Parameters Based on Genetic Algorithms for Spacecraft Attitude Tracking with Input Constraints. Neurocomputing, 2016, 177, 334-341. https://doi.org/10.1016/j.neucom.2015.11.022

14. Kim, S.-W., Park, S.-Y, Park, C. Spacecraft Attitude Control Using Neuro-Fuzzy Approximation of the Optimal Controllers. Advances in Space Research, 2016, 57, 137152. https://doi.org/10.1016/j.asr.2015.09.016

15. Zhao, L., Jia, Y. Neural Network-Based Distributed Adaptive Attitude Synchronization Control of Space- 
craft Formation Under Modified Fast Terminal Sliding Mode. Neurocomputing, 2016, 171, 230-241. https://doi. org/10.1016/j.neucom.2015.06.063

16. Mirshams, M., Khosrojerdi, M. Attitude Control of an Underactuated Spacecraft Using Tube-Based MPC Approach. Aerospace Science and Technology, 2016, 48, 140-145. https://doi.org/10.1016/j.ast.2015.09.018

17. Mazinan, A. H., Shakhesi, S. Autonomous Space Systems Control Incorporating Automated Maneuvers Strategies in the Presence of Parameters Uncertainties. ISA transactions, 2016, 62, 236-247. https://doi. org/10.1016/j.isatra.2016.01.012

18. Mazinan, A. H. Stability Analysis of Autonomous Space Systems in the Presence of Large Disturbances: A Lyapunov-Based Constrained Control Strategy. ISA Transactions, 2016, 61, 60-74. https://doi.org/10.1016/j.isatra.2016.01.007

19. Mazinan, A. H. On Comprehensive Cascade Control Strategy Considering a Class of Overactuated Autonomous Non-Rigid Space Systems with Model Uncertainties. Robotics and Autonomous Systems, 2016. https:// doi.org/10.1016/j.robot.2015.12.004

20. Mazinan, A. H. High-Performance Robust Three-Axis Finite-Time Attitude Control Approach Incorporating Quaternion Based Estimation Scheme to Overactuated Spacecraft. International Journal of Engineering-Transactions A, 2016, 29, 53-59. https://doi: 10.5829/idosi.ije.2015.29.1a.08

21. Ni, Z., Mu, R., Xun, G., Wu, Z. Time-Varying Modal Parameters Identification of a Spacecraft with Rotating Flexible Appendage by Recursive Algorithm. Acta Astronautica, 2016, 118, 49-61. https://doi.org/10.1016/j. actaastro.2015.10.001

22. Peng, H., Jiang, X. Nonlinear Receding Horizon Guidance for Spacecraft Formation Reconfiguration on Libration Point Orbits Using a Symplectic Numerical Method. ISA Transactions, 2016, 60, 38-52. https://doi. org/10.1016/j.isatra.2015.10.015

23. Stevenson, D., Schaub, H. Electrostatic Spacecraft Rate and Attitude Control - Experimental Results and Performance Considerations. Acta Astronautica, 2016, 119, 22-33. https://doi.org/10.1016/j.actaastro.2015.10.023
24. Schwartz, S. R., Yu, Y., Patrick, M., Jutzi, M. Small-Body Deflection Techniques Using Spacecraft: Techniques in Simulating the Fate of Ejecta. Advances in Space Research, 2016, 57, 1832-1846. https://doi.org/10.1016/j. asr.2015.12.042

25. Sidi, M. J. Spacecraft Dynamics and Control: A Practical Engineering Approach. Cambridge University Press, 1997. https://doi.org/10.1017/CBO9780511815652

26. Shahi, M., Mazinan, A. H. Monte-Carlo Based Cascade Control Approach with a Focus on Real Overactuated Spacecraft. Journal of Central South University of Technology, 2016, 23, 3171-3182. https://doi. org/10.1007/s117r71-016-3383-7

27. Schulte, P. Z., Spencer, D. A. Development of an Integrated Spacecraft Guidance, Navigation \& Control Subsystem for Automated Proximity Operations. Acta Astronautica, 2016, 118, 168-186. https://doi.org/10.1016/j. actaastro.2015.10.010

28. Wang, X., Qin, W., Bai, Y., Cui, N. A Novel Decentralized Relative Navigation Algorithm for Spacecraft Formation Flying. Aerospace Science and Technology, 2016, 48, 28-36. https://doi.org/10.1016/j.ast.2015.10.014

29. Zou, A.-M., de Ruiter, A. H. J., Kumar, K. D. Distributed Attitude Synchronization Control for a Group of Flexible Spacecraft Using Only Attitude Measurements. Information Sciences, 2016, 343-344, 66-78. https://doi. org/10.1016/j.ins.2016.01.048

30. Zou, A.-M., de Ruiter, A. H. J., Kumar, K. D. Distributed Finite-Time Velocity-Free Attitude Coordination Controlfor Spacecraft Formations. Automatica, 2016, 67, 4653. https://doi.org/10.1016/j.automatica.2015.12.029

31. Zhang, X., Liu, X., Zhu, Q. Attitude Stabilization of Rigid Spacecraft with Disturbance Generated by Time Varying Uncertain Exosystems. Communications in Nonlinear Science and Numerical Simulation, 2016, 35, 25-36. https://doi.org/10.1016/j.cnsns.2015.11.004

32. Zhang, F., Duan, G. R. Integrated Translational and Rotational Finite-Time Maneuver of a Rigid Spacecraft with Actuator Misalignment. IET Control Theory Application, 2012, 6(9), 1192-1204. https://doi. org/10.1049/iet-cta.2011.0413 


\section{Summary / Santrauka}

What we research here deals with the dynamics and its kinematics concerning the autonomous space systems through a new control strategy, while a band of parameters uncertainties in connection with disturbances based upon the variations of the thrust vector, center of mass, engine misalignment, moments of inertial and so on are all taken into real consideration. To present the investigated outcomes in such a real situation, the process noise that is related to a set of thrusters and the measurement noise that also is related to a set of sensors are considered to be dealt with through optimal state estimator scheme. There are the double control loops including the inner loop and the outer loop, which are organized based upon a combination of low and high thrusts levels to handle three-axis rotational angles and their rates. The aforementioned thrusts levels in connection with the uncertainties and disturbances are handled through the Monte-Carlo based method to consider the performance of the proposed approach, in a series of experiments. The investigated results show that the performance of the proposed strategy is verified in which the well-known state-dependent Riccati equation based on the three-axis rotational angles and the corresponding angular rates as well as a number of potential benchmarks are considered to be compared in the same conditions as much as possible.

Taikant naują kontrolès strategiją, straipsnyje analizuojama autonominių erdvių sistemų dinamika ir jos kinematika. Realiai atsižvelgiama į grupę parametrų neapibrěžtumų, susijusių su trikdžiais, kylančiais dèl traukos vektoriaus variacijų, masės centro, variklio poslinkio, inercinių momentų ir pan. Norint pateikti tiriamus realios situacijos rezultatus, proceso triukšmas, susijęs su greitintuvais, ir matavimo triukšmas, susijęs su jutikliais, yra aptariamas taikant optimalią būklès įvertinimo schemą. Schemoje yra dvigubos kontrolès kilpos, įskaitant vidinę ir išorinę, kurios tam, kad būtų galima valdyti trijų ašių sukimosi kampus ir jų dydị, yra sudarytos remiantis žemos ir aukštos traukos lygiais. Ankščiau minėtieji su neapibrèžtumu ir trikdžiais susiję traukos lygiai sprendžiami naudojant Monte-Karlo metodą. Taip atliekant serijinius eksperimentus siekiama įvertinti siūlomo metodo veiksmingumą. Metodo našumas įrodomas kiek įmanoma vienodesnėmis sąlygomis lyginant gerai žinomą nuo būsenos priklausomą, trijų ašių sukimosi kampais grịstą Rikati lygtį, atitinkamus kampų dydžius bei potencialių etalonų skaičių. 